\title{
Luddites, the Industrial Revolution, and the Demographic Transition*
}

\author{
Kevin H. O'Rourke, Ahmed S. Rahman, and Alan M. Taylor ${ }^{\dagger}$
}

July 2012

${ }^{*}$ We acknowledge funding from the European Community's Sixth Framework Programme through its Marie Curie Research Training Network programme, contract numbers MRTN-CT-2004-512439 and HPRN-CT-2002-00236. We also thank the Center for the Evolution of the Global Economy at the University of California, Davis, for financial support. O'Rourke would like to thank the European Research Council for its financial support, under its Advanced Investigator Grant scheme, contract number 249546. Some of the work on the project was undertaken while O'Rourke was a Government of Ireland Senior Research Fellow and while Taylor was a Guggenheim Fellow; we thank the Irish Research Council for the Humanities and Social Sciences and the John Simon Guggenheim Memorial Foundation for their generous support. For their helpful criticisms and suggestions we thank Gregory Clark, Oded Galor, Philippe Martin, David Mitch, Joel Mokyr, Andrew Mountford, Joachim Voth, two anonymous referees, and participants in workshops at Royal Holloway, University of London; London School of Economics; Universidad Carlos III; University College, Galway; Paris School of Economics; and Brown University; and at the CEPR conferences "Europe's Growth and Development Experience" held at the University of Warwick, 28-30 October 2005, "Trade, Industrialisation and Development" held at Villa Il Poggiale, San Casciano Val di Pesa (Florence), 27-29 January 2006, and "Economic Growth in the Extremely Long Run" held at the European University Institute, 27 June-1 July, 2006; at the NBER International Trade and Investment program meeting, held at NBER, Palo Alto, Calif., 1-2 December 2006; and at the NBER Evolution of the Global Economy workshop, held at NBER, Cambridge, Mass., 2 March 2007. The latter workshop was supported by NSF grant OISE 05-36900 administered by the NBER. All errors are ours.

${ }^{\dagger} \mathrm{O}$ 'Rourke: University of Oxford, CEPR, and NBER (kevin.orourke@all-souls.ox.ac.uk). Rahman: United States Naval Academy (rahman@usna.edu). Taylor: University of Virginia, NBER, and CEPR (alan.m.taylor@virginia.edu) 


\title{
Luddites, the Industrial Revolution, and the Demographic Transition
}

\begin{abstract}
Technological change was unskilled-labor-biased during the early Industrial Revolution, but is skill-biased today. This implies a rich set of non-monotonic macroeconomic dynamics which are not embedded in extant unified growth models. We present historical evidence and develop a model which can endogenously account for these facts, where factor bias reflects profit-maximizing decisions by innovators. In a setup with directed technological change, and fixed as well as variable costs of education, initial endowments dictate that the early Industrial Revolution be unskilledlabor-biased. Increasing basic knowledge then causes a growth takeoff, an incomeled demand for fewer but more educated children, and a transition to skill-biased technological change in the long run.
\end{abstract}

Keywords: skill bias, directed technological change, endogenous growth, demography, unified growth theory.

JEL Codes: $\mathrm{O}_{31}, \mathrm{O}_{33}, \mathrm{~J}_{13}, \mathrm{~J} 24, \mathrm{~N} 10$. 
On March 11, 1811, several hundred framework knitters gathered in the Nottingham marketplace, not far from Sherwood Forest, to protest their working conditions. Having been dispersed by the constabulary and a troop of Dragoons, they reassembled that evening in nearby Arnold, and broke some sixty stocking frames. On November 10 of the same year, another Arnold mob gathered in Bulwell Forest, under the command of someone styling himself "Ned Lud," and the rapidly growing Luddite movement would suffer its first fatality that night when John Westley was shot dead during an attack on the premises of Edward Hollingsworth, a local hosier.

Today, the term Luddite often refers to opponents of technological progress for its own sake. At the time, however, Luddites were engaged in what Hobsbawm (1952, p. 59) has termed "collective bargaining by riot." "In none of these cases ... was there any question of hostility to machines as such. Wrecking was simply a technique of trade unionism" (ibid.) on the part of skilled textile workers whose living standards were being eroded by new machinery. This new machinery was making it possible for employers not just to produce cloth more efficiently, but to use cheaper unskilled workers-women, and even children - in the place of highly paid artisans. Not surprisingly, skilled workers objected to this.

Luddism emerged during what Galor and Weil (2000) have termed the "post-Malthusian regime." During this phase of British economic history, technological change was enabling the economy to gradually escape the Malthusian trap. However, living standards only rose slowly during this period, as population grew at an accelerating rate. But by the late 19th century, technological change was accelerating and living standards were growing more rapidly (Figure 1). Much of this acceleration was due to a dramatic and well-documented demographic transition, whereby fertility rates fell and educational standards rose (Figure 2). Many new technologies were by then beginning to emerge which were skill-using rather than skill-saving, for example in modern chemical and metallurgical industries.

A standard assumption in unified growth theory (UGT) is that modern economic growth (MEG) is characterized by the development of skill-using technologies. That this is a sensible assumption for the 2oth century has been abundantly documented in Goldin and Katz (2008) for the United States, for example, but this is certainly not only an American story (see for example Berman, Bound, and Machin 1998). So, in the sufficiently recent past, technological progress has been skill-using. However, as the example of the Luddites shows, we cannot assume that this has always been the case. Indeed, Acemoglu (2002), surveying the literature, concludes that the notion that technical change is skill-biased is appropriate for the 2oth century, but not for earlier 
Figure 1: Growth Rates of GDP per Capita and Population in Western Europe, 1500-2000

The figure shows two key long-run stylized facts: the permanent acceleration in output per capita growth rates, and the temporary boom in population growth rates which accompanied the Industrial Revolution.

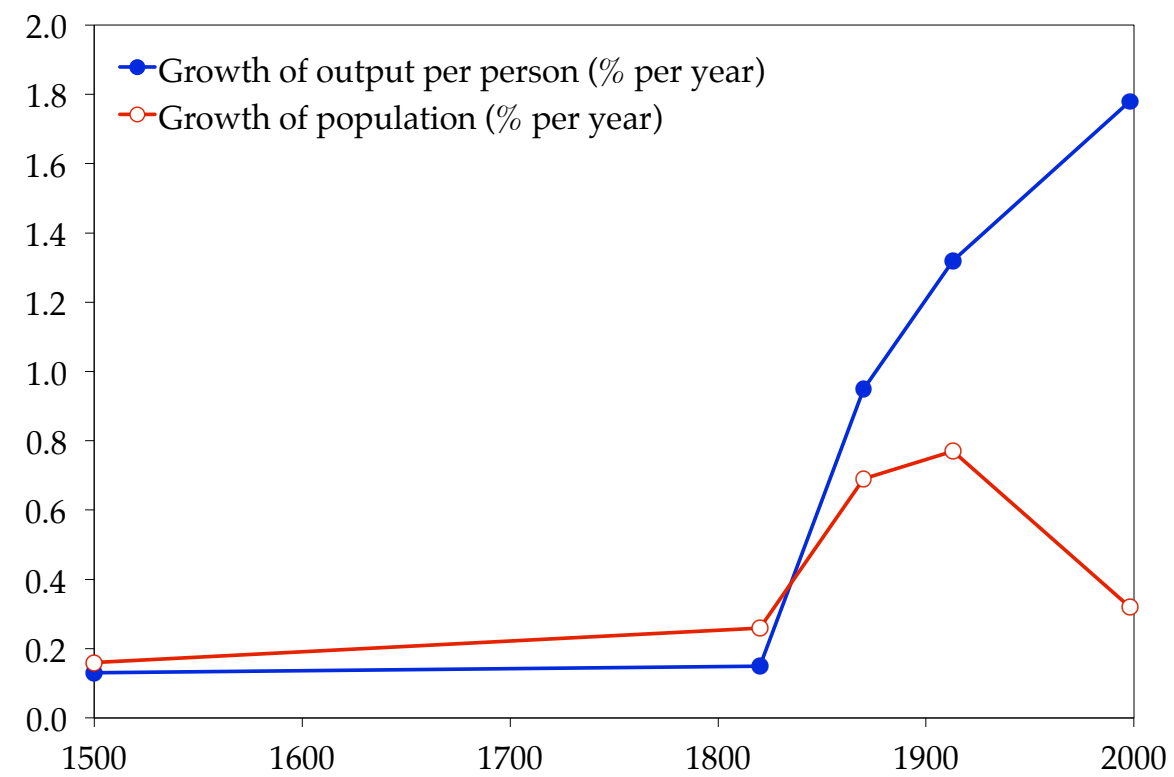

Source: Galor (2005), based on Maddison (2001).

periods. And there are good grounds for believing that in the sufficiently early stages of the British Industrial Revolution, technological progress in industries like textiles was skill-saving rather than skill-using.

For example, by way of initial conditions, preindustrial textile production needed highly skilled labor such as spinners and weavers. Similarly, other preindustrial manufactures relied on their own skilled artisans of various sorts. But implementing the technologies of the Industrial Revolution (in textile production, iron smelting and refining, mining and agriculture) required large labor forces with little to no specialized training. In some cases it is very easy to see the motivation as well as the impact of innovation. For example, Richard Roberts's invention of the self-acting mule came about as a result of a plea for help on the part of Manchester cotton manufacturers, faced with a mule spinners strike (Rosenberg 1969, p. 13), and this was not the only example of a skilled-labor-saving invention brought about as a result of the efforts of skilled workers to maintain their relative economic position (ibid.). Important recent work by leading economic historians has highlighted the displacement of highly-paid adult labour during the British Industrial Revolution. Allen (2009) has stressed the labour-saving na- 


\section{Figure 2: Fertility and Schooling in Four Advanced Countries}

The figures show two key correlates of the Industrial Revolution: fertility decreased (the Demographic Transition) and education increased. However, the transtions did not occur until later in the 19th century.

(a) England and Wales

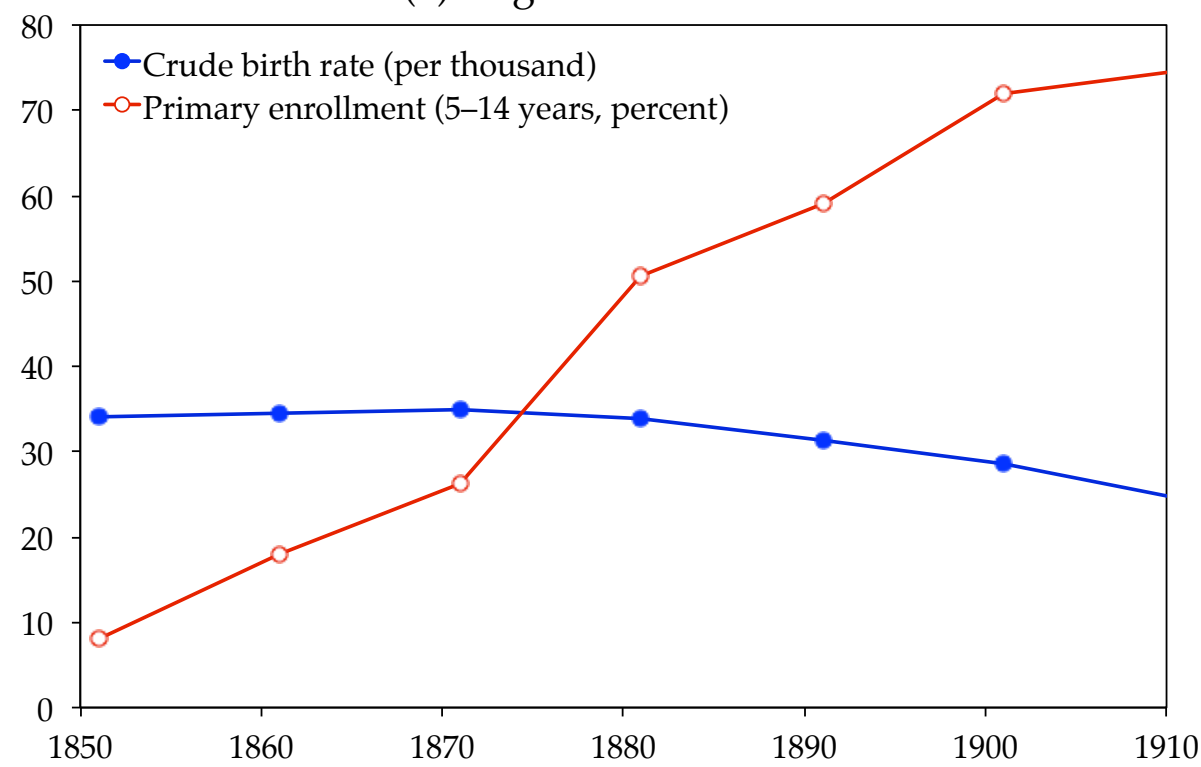

(b) Germany

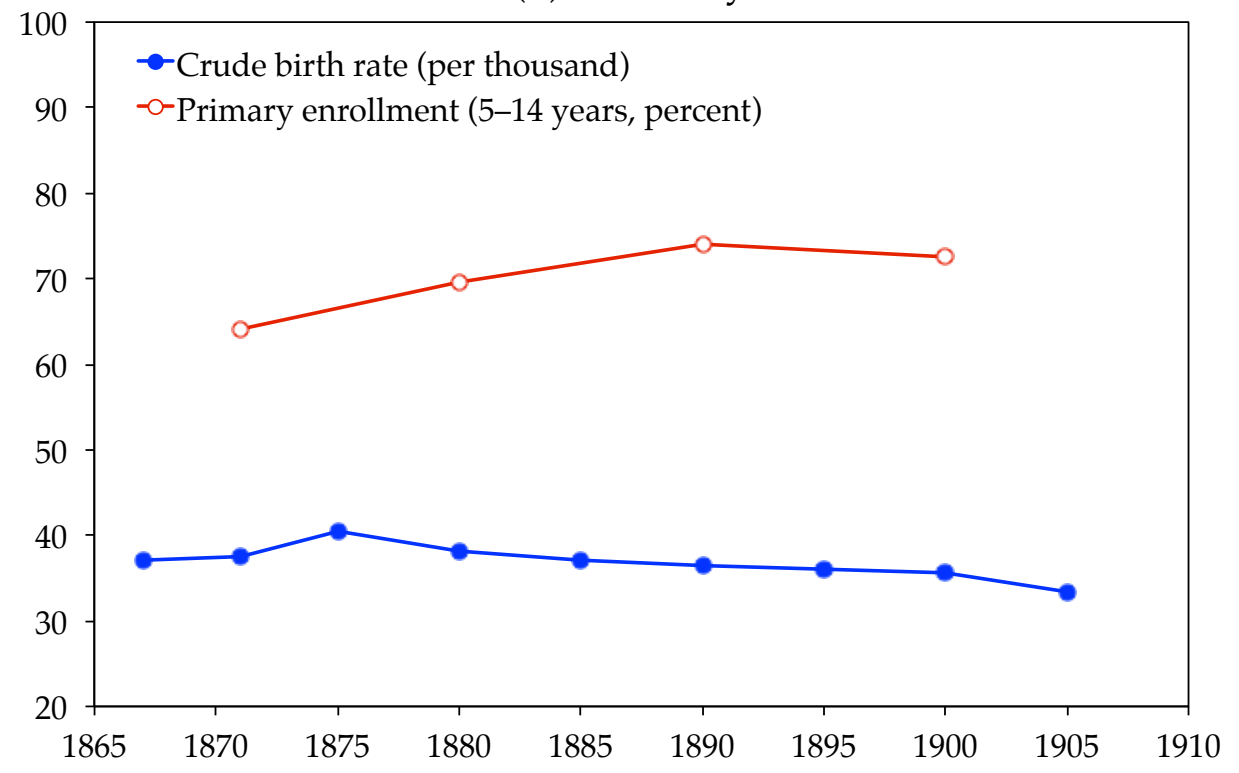


Figure 2 (continued): Fertility and Schooling in Four Advanced Countries

(c) Sweden

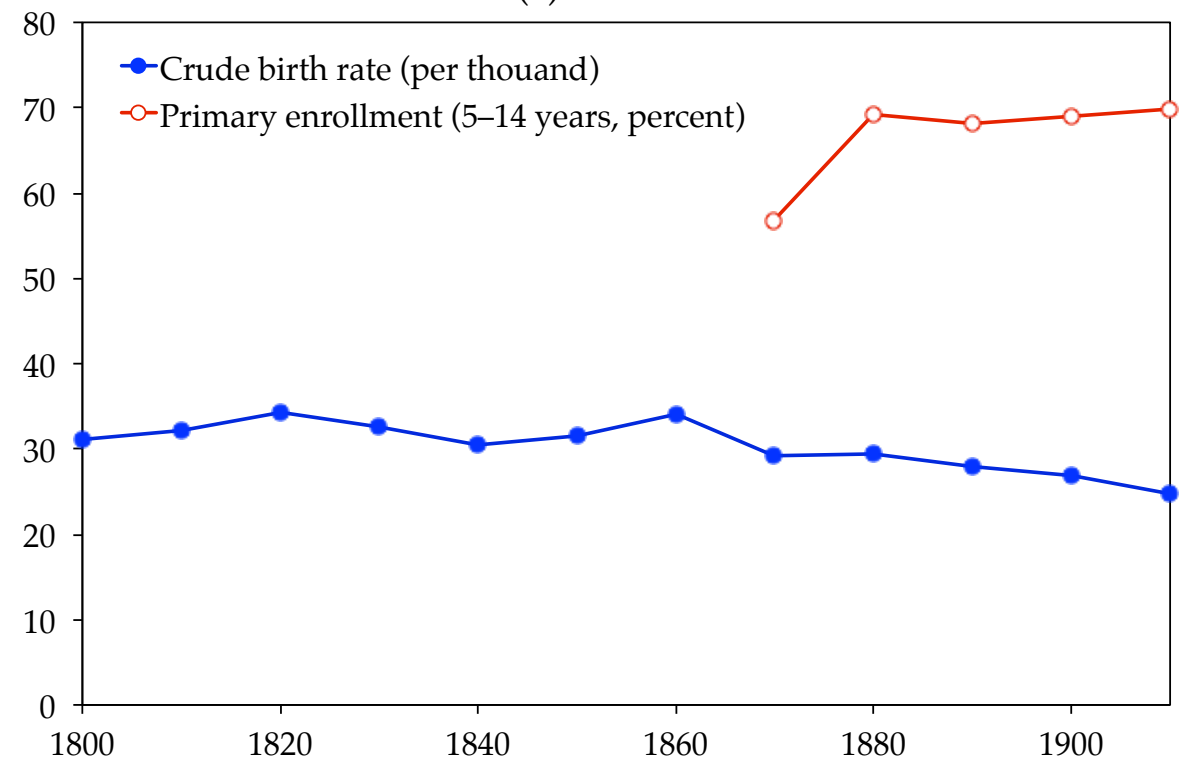

(d) United States

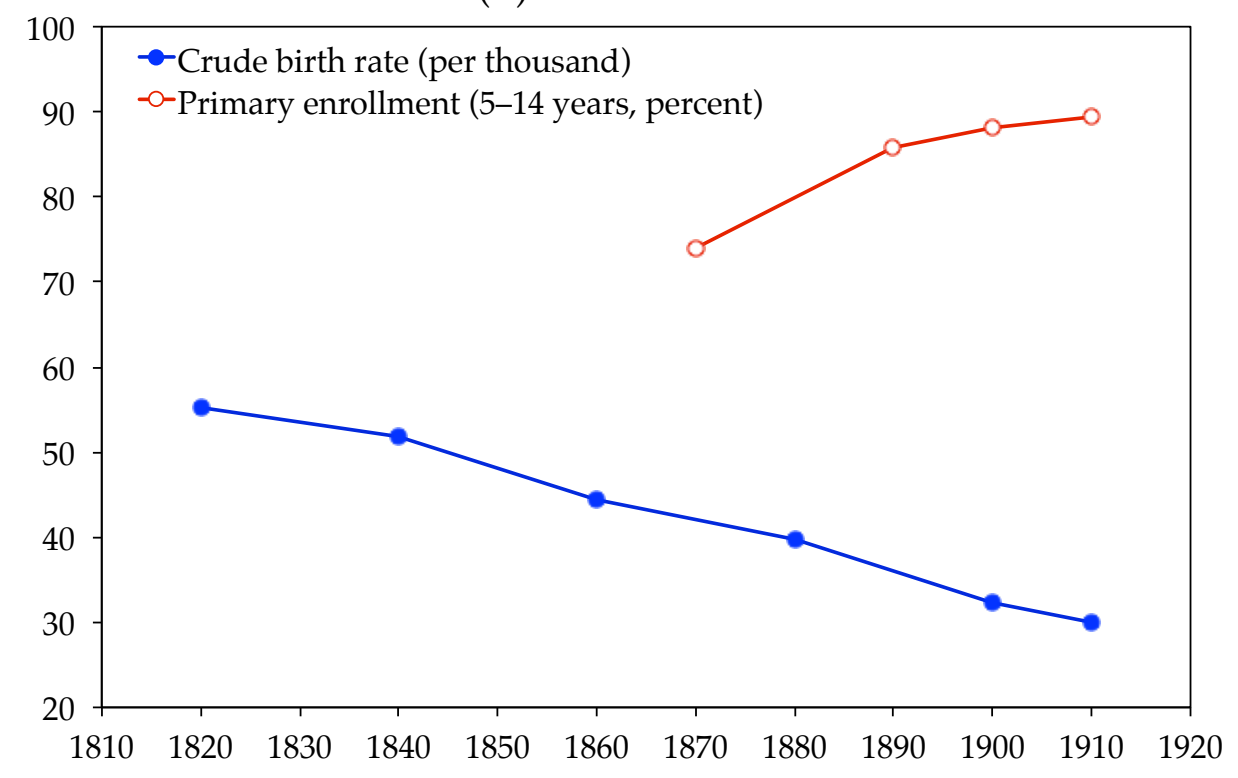

Source: Tan and Haines (1984). Trend lines are 2-period moving averages. 
ture of technological change during this period, motivated by high British wages; while Humphries (2010) has emphasised the crucial role played by low-skilled child labour in the early stages of the Industrial Revolution. According to her (p. 43), mechanization, by "destroying jobs and making skills irrelevant", not only contributed to a temporary stagnation in adult wages, but increased both the demand for child labour (which displaced skilled adult labour) and the supply of it as well (by making families' economic situations more precarious). A recent paper by Boberg-Fazlic and Weisdorf (2012), based on a study of over 20,000 occupational records from Anglican parishes between 1550 and 1850, finds that while only one in five English workers were unskilled prior to 1700 , almost half were engaged in unskilled work by 1850 .

Nor was this a uniquely British phenomenon, as unskilled labour, capital, and natural resources were substituted for skilled labour in mid-nineteenth century American industry as well (this is a core tenet of American economic history: see, e.g., seminal work by James and Skinner 1985). Furthermore, this process continued during the rest of the nineteenth century in other industries. As Mokyr (1990, p. 137) puts it, after the U.S. Civil War, first in the U.S., and then in Europe, mass production methods gradually displaced skilled workers in a broad range of sectors: "First in firearms, then in clocks, pumps, locks, mechanical reapers, typewriters, sewing machines, and eventually in engines and bicycles, interchangeable parts technology proved superior and replaced the skilled artisans working with chisel and file." Through these kinds of long-run processes happy, highly-valued skilled craftsmen became angry, machine-breaking Luddites.

Much later, fortunes changed: many the techniques developed in the latter half of the 19th century (for example in chemicals, electrical industries and services) raised the demand for a new labor force with highly specialized skills (Mokyr 1999). The industries of the Second Industrial Revolution were not only based on an increasingly formal interaction between science and industry, but required an increased supply of well- trained chemists, engineers, and other high-skill workers as well. According to Goldin and Katz (2008), in the early 2oth century (or from as early as the 1890s, in certain sectors) American manufacturers began to adopt continuous-process or batch production methods, associated with new electricity- and capital-intensive technologies. These new technologies increased the relative demand for skilled workers, who were required to operate the new machinery, and ceteris paribus raised the return to skills. Again the story is not confined to one country. For example, an inability to match Germany in the training of high-skill workers essential for new industries has long been thought to be a factor in relative British decline during this period (e.g., see the references in Mokyr 2002, p. 274). 
If in the sufficiently distant past, technological progress was on average skill-saving, but in the sufficiently recent past it has become on average skill-using, then it logically follows that at some point there was a transition from (on average) skill-saving to skillusing technical change. This transition presumably happened over a long period of time, with turning points occurring in different periods in different countries, and at different times in different sectors.

The challenge to history and theory is then to explain how and why this happened. The main purpose of this paper is to show how such a transition could have occurred, within the context of a UGT model. Since in reality the transition was not abrupt, but took place over a protracted period of time, we will want our model to generate a longdrawn-out transition period, during which both skill-saving and skill-using technological change occurred, but with the relative share of the former decreasing, and of the latter increasing, over time. In order to achieve this this, we need to go beyond the current UGT literature (e.g., Galor and Weil 2000; Jones 2001; Hansen and Prescott 2002; Lucas 2002; Weisdorf 2004; Galor 2011) in several respects.

Most obviously, we need to incorporate two types of workers, skilled and unskilled, so that technological change can be biassed in either direction. Second, we need to allow for factor-biased technological change. Third, and most importantly, we need to allow the direction of factor bias to differ at different points in time, since we want to explain why the Industrial Revolution was initially so bad for skilled workers, rather than simply assume this was the case. Similarly, we want to explain why, by the end of the 19th century, new technologies that were skill-using were being invented, rather than just assume this was happening. We are thus going to have to explicitly model the choices facing would-be innovators. If the direction of technological change differed over time, this presumably reflected the different incentives facing these inventors. ${ }^{1}$

In this paper, we thus delve into the microeconomics of technological change to a greater extent than previous unified growth theory papers, which have tended to model technological change in a reduced form manner as a function of scale affects (cf. Romer 1990, Kremer 1993) and/or human capital endowments. We propose a fully-specified research and development model driving technological change, which is appropriate for this period since Allen (2006) has recently pointed out that British firms were investing

\footnotetext{
${ }^{1}$ Some existing models, notably Galor and Weil (2000), do allow for an endogenous link between technological change and skill premia, in that they assume that technological change is in itself skill- biased (in the sense that educated agents have an advantage in adapting to changed technological environments). We do not incorporate this short run link between technological change and skill-biasedness in our model, so as to focus on the long run skill-biased or skill-saving nature of new technologies. Naturally, a more complete model could incorporate both mechanisms.
} 
significant resources in the search for technological breakthroughs during the Industrial Revolution. Building on the foundations of the benchmark Galor-Weil (2000) and GalorMountford (2008) models, we thus make several key changes to previous specifications.

The first key feature of our model, and the paper's main contribution, is that it endogenizes the direction of technological change. There are two ways to produce output, using either a low-skill technique (based on raw labor $L$ ) or a high-skill technique (based on educated labor or human capital $H$ ). For simplicity, these techniques are each linear in their sole input, and are characterized by their own, endogenous, productivity coefficients or technology levels.

Research by firms, which is patentable or otherwise excludable in the short run, can raise these technology levels and generate short-run monopoly profits. In the spirit of Acemoglu (1998), we allow potential innovators to look at the supply of skilled and unskilled labor in the workforce, and tailor their research efforts accordingly. The direction as well as the pace of technological change thus depends on demography. At the same time, demography is explicitly modeled as depending on technology, as is common in the literature (e.g., Galor and Weil 2000). Households decide the quality and quantity of their children (that is, the future supply of $L$ and $H$ ) based directly on anticipated future wages, and thus (indirectly) on recent technological developments. As such the model allows for the co-evolution of both factors and technologies.

The second key feature of our approach is that we distinguish between two different types of technological progress: basic knowledge $(B)$ and applied knowledge $(A)$. In our model, the former grows according to the level of human capital in the economy and is a public good; the latter describes firms' techniques, which are subject (for a time) to private property rights, generate private profits, and hence create incentives for research. In our model, $A$ is driven by research which generates benefits (increases in $A$ ) but also has costs (that are decreasing in $B$ ); thus basic knowledge drives the development of applied knowledge.

This distinction between basic and applied knowledge is inspired by Mokyr (2002, 2005a), who distinguishes between two knowledge types: the "propositional" episteme ("what") and the "prescriptive" techne ("how"). An addition to the former is for Mokyr a discovery, and an addition to the latter an invention. These categories can be thought of as close parallels to our B-knowledge (which we also call "Baconian" knowledge) and $A$-knowledge (our sector-specific productivity levels, or TFP). We propose the term Baconian knowledge to honor Francis Bacon, since if Mokyr (2002, p. 41) is correct, then "the amazing fact remains that by and large the economic history of the Western world was dominated by materializing his ideals." Our model can provide a rationale 
for one of Mokyr's key claims, namely that "the true key to the timing of the Industrial Revolution has to be sought in the scientific revolution of the seventeenth century and the enlightenment movement of the eighteenth century" (p. 29). As will be seen, basic knowledge has to advance in our model for some time before applied knowledge starts to improve. This helps the model match reality: we find that Baconian knowledge $B$ can increase continuously, but applied knowledge or productivity $A$ only starts to rise in a discontinuous manner once $B$ passes some threshold.

The third key feature of our model is that it embodies a fairly standard demographic mechanism, in which parents have to trade off between maximizing current household consumption and the future skilled income generated by their children. We get the standard result that, ceteris paribus, a rising skill premium implies rising educational levels and falling fertility levels, while a falling skill premium implies the reverse. However, we further assume that rising wages makes education more affordable for households, an effect which accords with documented evidence on schooling costs in the mid-19th century. Thus our model suggests that robust technological growth during the late 19th century fostered the dramatic rise in education and fall in fertility, and could do so even without skill premia rising.

The next section of the paper presents the key aspects of the model, which endogenizes both technologies and demography. We then simulate this model to show how the theory can track the key features of the industrialization of Western Europe during the 18th and 19th centuries.

\section{The Model}

In this section we build a theoretical version of an industrializing economy in successive steps, keeping the points enumerated in the introduction firmly in mind. Section 1.1 goes over the production function and technologies. Here we develop a method for endogenizing the scope and direction of technical change, keeping endowments fixed. Section 1.2 then merges the model with an overlapping generations framework in order to endogenize demographic choices, and hence endowments, taking technology as given. These two parts will then form an integrated dynamic model which we use to analyze the industrialization of England during the 18th and 19th centuries. 


\subsection{Technology and Production}

We begin by illustrating the static general equilibrium of a hypothetical economy. The economy produces a final good $Y$ out of two "intermediate inputs" using a CES production function

$$
Y=\left(\left(A_{l} L\right)^{\frac{\sigma-1}{\sigma}}+\left(A_{h} H\right)^{\frac{\sigma-1}{\sigma}}\right)^{\frac{\sigma}{\sigma-1}}
$$

where $A_{l}$ and $A_{h}$ are technology terms, $L$ is unskilled labor, $H$ is skilled labor, and $\sigma$ is the elasticity of substitution between the two intermediate inputs. Heuristically, one might think of the final good $Y$ as being "GDP" which is simply aggregated up from the two intermediates.

By construction, $A_{l}$ is L-augmenting and $A_{h}$ is H-augmenting. We will assume throughout the paper that these intermediates are grossly substitutable, and thus assume that $\sigma>1 .^{2}$ With this assumption of substitutability, a technology that augments a particular factor is also biased towards that factor. Thus we will call $A_{l}$ unskilled-labor-biased technology, and $A_{h}$ skill-biased technology.

Economic outcomes heavily depend on which sectors enjoy superior productivity performance. Some authors use loaded terms such as "modern" and "traditional" to label the fast and slow growing sectors, at least in models where sectors are associated with types of goods (e.g., manufacturing and agriculture). We employ neutral language, since we contend that growth can emanate from different sectors at different times, where 'sectors' in our model are set up to reflect factor biases in technology. We argue that the unskilled-intensive sector was the leading sector during the early stages of the Industrial Revolution, while the skilled-intensive sector significantly modernized only from the mid-180os onwards.

We assume that markets for both the final good and the factors of production are perfectly competitive. Thus, prices are equal to unit costs, and factors are paid their marginal products. We can then describe wages as

$$
\begin{gathered}
w_{l}=\left(\left(A_{l} L\right)^{\frac{\sigma-1}{\sigma}}+\left(A_{h} H\right)^{\frac{\sigma-1}{\sigma}}\right)^{\frac{1}{\sigma-1}} L^{-\frac{1}{\sigma}} A_{l}^{\frac{\sigma-1}{\sigma}}, \\
w_{h}=\left(\left(A_{l} L\right)^{\frac{\sigma-1}{\sigma}}+\left(A_{h} H\right)^{\frac{\sigma-1}{\sigma}}\right)^{\frac{1}{\sigma-1}} H^{-\frac{1}{\sigma}} A_{h}^{\frac{\sigma-1}{\sigma}} .
\end{gathered}
$$

${ }^{2}$ This has become a rather standard assumption in the labor literature, and is an important one for our analysis later. 
which in turn implies that the skill premium, $w_{h} / w_{l}$, can be expressed as

$$
\frac{w_{h}}{w_{l}}=\left(\frac{L}{H}\right)^{\frac{1}{\sigma}}\left(\frac{A_{h}}{A_{l}}\right)^{\frac{\sigma-1}{\sigma}}
$$

From the above we can see that, so long as the maintained assumption $\sigma>1$ holds, and holding fixed the supply of factors $H$ and $L$, a rise (fall) in $A_{h}$ relative to $A_{l}$ implies a rise (fall) in the demand for skilled labor relative to unskilled labor, and in our model this will generate a rise (fall) in the skill premium, all else equal. Similarly, holding $A_{h}$ and $A_{l}$ constant, a rise (fall) in $H / L$ will lead to a fall (rise) in the skill premium, all else equal. Later on, however, as we develop our model, we will explore how supplies of factors change endogenously in the long run in response to changes in the skill premium. For the moment, we begin by developing a model of how changes in the technology parameters $A_{h}$ and $A_{l}$ themselves will depend, among other things, on factor supplies and wage rates.

In order to endogenize the evolution of factor-specific technology levels $A_{l}$ and $A_{h}$, we model technological development as improvements in the quality of machines, as in Acemoglu (1998). Specifically, we assume that researchers expend resources to improve the quality of a machine, and receive some positive profits (due to patents or first-mover advantage) from the sale of these new machines for only one time period. ${ }^{3}$ We then define the productivity levels $A_{l}$ and $A_{h}$ to be amalgamations of quality-adjusted machines that augment either unskilled labor, or skilled labor, but not both.

In our model, costly innovation will be undertaken to improve some machine $j$ (designed to be employed either by skilled or unskilled labor), get the blueprints for this newly improved machine, use these blueprints to produce the machine, and sell these machines to the producers of the intermediate good. After one period, however, new researchers can enter the market, and we find that newer, better machines will drive out the older designs. In this fashion we simplify the process of "creative destruction" (Schumpeter 1934, Aghion and Howitt 1992) whereby successful researchers along the quality dimension tend to eliminate the monopoly rents of their predecessors.

\footnotetext{
${ }^{3}$ Conceptually one could assume either that patent rights to innovation last only one time period, or equivalently that it takes one time period to reverse-engineer the development of a new machine. In any case, these assumptions fit the historical evidence that profits from inventive activity were typically short-lived during the Industrial Revolution (Clark 2007).
} 


\section{Intermediate Goods Production}

Let us now make technology levels explicit functions of these quality-adjusted machines. $A_{l}$ and $A_{h}$ at time $t$ are defined as the following:

$$
\begin{aligned}
A_{l} & \equiv \frac{1}{1-\beta} \int_{0}^{1} q_{l}(j)\left(\frac{M_{l}(j)}{L}\right)^{1-\beta} d j, \\
A_{h} & \equiv \frac{1}{1-\beta} \int_{0}^{1} q_{h}(j)\left(\frac{M_{h}(j)}{H}\right)^{1-\beta} d j,
\end{aligned}
$$

where $0<\beta<1 . M_{l}$ are machines that are strictly employed by unskilled workers, while $M_{h}$ are machines that are strictly employed by skilled workers. $q_{z}(j)$ is the highest quality of machine type $j$ used in sector $z$. The index $j$ runs over $[0,1]$, and $z \in\{l, h\}$. Note that these technological coefficients may thus be interpreted simply as functions of different types of 'capital per worker' in each sector $z$; however, the capital in this case is specialized and quality-adjusted. The specifications here imply constant returns to scale in the production of the skilled- and unskilled-intensive intermediate goods.

In the end, we care less about micro differences in machine qualities than about macro effects on total factor productivity. To draw conclusions about the latter we note that our problem will have a symmetric equilibrium at the sector level, implying that aggregation is straightforward. In particular, all machines indexed by $j$ in the $(0,1)$ continuum will on average be of symmetric quality, as inventors will be indifferent as to which particular machines along the continuum they will improve. As such we can alternatively write equations (5) and (6) as

$$
\begin{aligned}
& A_{l} \equiv\left(\frac{1}{1-\beta}\right) Q_{l} \int_{0}^{1}\left(\frac{M_{l}(j)}{L}\right)^{1-\beta} d j, \\
& A_{h} \equiv\left(\frac{1}{1-\beta}\right) Q_{h} \int_{0}^{1}\left(\frac{M_{h}(j)}{H}\right)^{1-\beta} d j,
\end{aligned}
$$

where $Q_{z}$ simply denotes the uniform and symmetric quality of all machine types $j$ used in sector $z \in\{l, h\}$. The term $Q_{z}$ can therefore be taken outside the integral. Increases in this index directly increase the total factor productivity of sector $z$. We also assume that machines last one period, and then depreciate completely.

Now consider a representative firm that competitively produces the unskilled intermediate. (For brevity, much of what follows will deal with only this L-using unskilled sector. Analogous results hold for the $H$-using skilled sector.) The firm's maximization problem is stated as 


$$
\max _{\left\{L, M_{l}(j)\right\}} p_{l} \cdot A_{l} L-\int_{0}^{1} p(j) M_{l}(j) d j-w_{l} L,
$$

where $p_{l}$ is the price of the unskilled-intensive intermediate good, and $p(j)$ is the price of machine $M_{l}(j)$ faced by all producers of the intermediate. Hence the firm chooses an amount of unskilled labor to hire and amounts of complementary machines to employ, taking the price of its output, the price of machines, and the price of raw labor as given.

From the first order condition on $L$ we have

$$
p_{l} \beta A_{l}=w_{l}
$$

Solving for the price of the intermediate we have $p_{l}=\frac{w w_{l}}{\beta A_{l}}$. From the first order condition on machine $j$ we can get the total demand for machine $M_{l}(j)$

$$
M_{l}(j)=\left(\frac{Q_{l} w_{l}}{\beta A_{l} p(j)}\right)^{\frac{1}{\beta}} L
$$

\section{The Gains from Innovation}

Innovation in a sector takes the form of an improvement in the quality of a machine by a certain multiple. Innovators expend resources up front to develop new machineblueprints, which they use to produce and sell a better-quality machine (all in the same time period). We assume that innovation is deterministic; that is, individuals who decide to do research will improve the quality of a machine with a probability of one. We also assume that there is a 'quality ladder' with discretely-spaced rungs. If innovation in sector $j$ occurs, the quality of machine $j$ will deterministically rise to $\varepsilon Q_{l}$, where $\varepsilon>1$ denotes the factor by which machine quality can rise. If on the other hand innovation does not occur, the quality of machine $j$ remains at $Q_{l}$. If someone does go ahead and innovate, they are assumed to have sole access to the blueprint for one period; after that the blueprint is public.

Once the researcher spends the resources necessary to improve the quality of machine $j$, she becomes the sole producer of this machine, and charges whatever price (call it $p(j))$ she sees fit. Thus she receives total revenue of $p(j) M_{l}(j)$. Here we must make the distinction between the cost of producing a machine, and the cost of inventing a machine. We discuss the costs of innovation in the next sub-section. Here, we assume that the marginal cost of producing a machine is proportional to its quality, so that better machines are more expensive to make-a form of diminishing returns. Indeed, we can normalize this cost, so that total costs are simply $Q_{l} M_{l}(j)$. 
Thus the producer of a new unskilled-using machine will wish to set the price $p(j)$ in order to maximize $V_{l}(j)=p(j) M_{l}(j)-Q_{l} M_{l}(j)$, where $V_{l}(j)$ is the value of owning the rights to the new blueprints of machine $j$ at that moment in time. The question for us is what this price will be. Note that it will not be possible for the owner to charge the full monopoly markup over marginal cost unless the quality increase $\varepsilon$ is very large. This is because all machines in sector $j$ are perfect substitutes (they are simply weighted by their respective qualities); by charging a lower price, producers of older lower-quality machines could compete with producers of newer higher-quality machines.

To solve the problem, we assume that producers of new machines engage in Bertrand price competition, in the spirit of Grossman and Helpman (1991) and Barro and Salai-Martin (2003). In this case the innovator and quality leader uses a limit-pricing strategy, setting a price that is sufficiently below the monopoly price so as to make it just barely unprofitable for the next best quality to be produced. This limit pricing strategy maximizes $V_{l}$ and ensures that all older machine designs are eliminated from current production.

In an appendix we describe in detail how we can solve for this price; here we simply note that our solution yields

$$
p(j)=p_{\text {limit }}=\varepsilon^{\frac{1}{1-\beta}} Q_{l}
$$

Note that this price is higher than the marginal cost of producing new machines, and so there is always a positive value of owning the blueprint to a new machine. Plugging this

price into machine demands and these machine demands into our expressions of $V_{l}$ and $V_{h}$ gives us

$$
\begin{aligned}
& V_{l}=\left(\varepsilon^{\frac{1}{1-\beta}+\left(\frac{1}{\beta}\right)\left(\frac{1}{\beta-1}\right)}-\varepsilon^{\left(\frac{1}{\beta}\right)\left(\frac{1}{\beta-1}\right)}\right) Q_{l}\left(\frac{w_{l}}{\beta A_{l}}\right)^{\frac{1}{\beta}} L=\Psi Q_{l}\left(\frac{w_{l}}{\beta A_{l}}\right)^{\frac{1}{\beta}} L,
\end{aligned}
$$

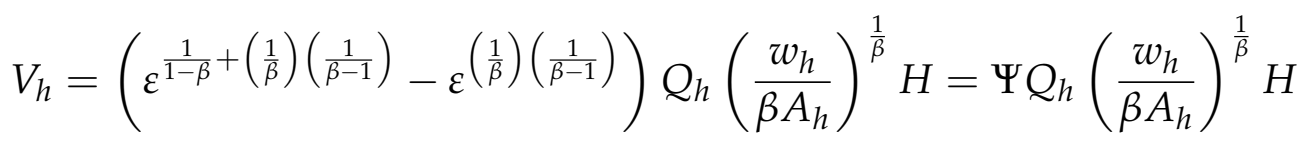

for unskilled-using and skilled-using machines, respectively. Notice that $\Psi$ is simply a constant greater than zero.

\section{The Costs of Innovation}

Before an innovator can build a new machine, she must spend resources on R\&D to first get the blueprints. Let us denote these costs as $c_{l}$ (for a new unskilled-labor using 
machine).

The resource costs of research will evolve due to changing economic circumstances. Specifically, the "price" of a successful invention should depend on things like how complicated the invention is and how "deep" general knowledge is. To capture some of these ideas, let us assume that the resource costs of research to improve machine $j$ in the unskilled-intensive sector are given by

$$
c_{l}=Q_{l}^{\alpha} B^{-\phi},
$$

and that the resource costs of research to improve machine $j$ in the skilled-intensive sector are given by

$$
c_{h}=Q_{h}^{\alpha} B^{-\phi} .
$$

where $\phi>0$ and $\alpha>1$.

In this setup, $\alpha$ can be considered a "fishing-out" parameter-the greater is the complexity of existing machines, the greater is the difficulty of improving upon them (see Jones 1998 on the idea of fishing out). The variable $B$ is our measure of current general knowledge that we label Baconian knowledge. The general assumptions in each sector are that research is more costly the higher is the quality of machine one aspires to invent (another sort of diminishing returns), and the lower is the stock of general knowledge.

\section{Growth of Baconian Knowledge}

Baconian knowledge $B$ thus influences the level of technology $A$. But what are the plausible dynamics of $B$ ? We allow general knowledge to grow throughout human history, irrespective of living standards and independent of the applied knowledge embedded in technology levels. According to Mokyr (2005b, pp. 291-2), Bacon regarded "knowledge as subject to constant growth, as an entity that continuously expands and adds to itself." Accordingly, we assume that the growth in basic knowledge depends on the existing stock. Furthermore, we assume that Baconian knowledge grows according to how much skilled labor exists in the economy. ${ }^{4}$

Specifically, we assume the simple form:

$$
\triangle B_{t+1}=H_{t} \cdot B_{t} .
$$

Thus we assume that increases in general knowledge (unlike increases in applied knowledge) do not arise from any profit motive, but are rather the fortuitous by-product of the

\footnotetext{
${ }^{4}$ Galor and Mountford (2008) make a rather similar assumption.
} 
existence of a stock of skilled workers, as well as of accumulated stocks of Baconian knowledge. But in our model, as we shall see, a skilled worker is just an educated worker, so it is here that the link between productivity growth and human capital is made explicit.

We now have a mechanism by which growth in general knowledge $(B)$ can influence the subsequent development of applied knowledge $\left(A_{l}\right.$ and $\left.A_{h}\right)$. Our functional forms (15) and (16) assume that low Baconian knowledge entails large costs to machine improvement, while high Baconian knowledge entails lower costs. In our model, $B$ never falls since (17) ensures that changes in $B$ are nonnegative. Hence, general knowledge always expands. This is not a historically trivial assumption, although it is accurate for the episode under scrutiny: Mokyr (2005b, 338-9) notes that knowledge had been lost after previous "efflorescences" (Goldstone 2002) in China and Classical Antiquity, and states that "The central fact of modern economic growth is the ultimate irreversibility of the accumulation of useful knowledge paired with ever-falling access costs."

\section{Modeling the Beginnings of Industrialization}

Turning to the decision to innovate in the first place, we assume that individuals can spend resources on research to develop and build machines with one quality-step improvement. But they will do so only if it is profitable. Specifically, if $\pi_{i}=V_{i}-c_{i} \geq 0$ then research activity for $i$-type machines occurs, otherwise it does not. Thus,

$$
\begin{gathered}
Q_{l, t}= \begin{cases}\varepsilon Q_{l, t-1} & \text { if } \Psi\left(\frac{w_{l}}{\beta A_{l}}\right)^{\frac{1}{\beta}} L \geq Q_{l}^{\alpha} B^{-\phi}, \\
Q_{l, t-1} & \text { otherwise, }\end{cases} \\
Q_{h, t}= \begin{cases}\varepsilon Q_{h, t-1} & \text { if } \Psi\left(\frac{w_{h}}{\beta A_{h}}\right)^{\frac{1}{\beta}} H \geq Q_{h}^{\alpha} B^{-\phi}, \\
Q_{h, t-1} & \text { otherwise. }\end{cases}
\end{gathered}
$$

As these expressions make clear, applied innovations will not be profitable until Baconian knowledge reaches a certain critical threshold where benefits exceed costs. The natural world needs to be sufficiently intelligible before society can begin to master it (Mokyr 2002). Thus our model embodies the idea that growth in general Baconian knowledge is a necessary but not sufficient condition for output growth.

Finally, which type of applied innovations happen first? It turns out that due to a "market size" effect, the sector that innovates first will be the one using the abundant factor, since it is there that there is the greatest potential demand for new machines. We 
can state this result in the following proposition:

Proposition 1. If $Q_{l}=Q_{h}$ and $L>H$, initial technological growth will be unskilled-labor biased if and only if $\sigma>1$.

Proof. Given $Q_{l}=Q_{h}$, the costs of innovation are the same for skilled and unskilled-laborusing machines, and are falling at the same rate. Hence, to show that initial growth will be unskill-intensive, we must demonstrate that initial conditions are such that $V_{l}>V_{h}$.

First, note that we can plug the limit price from (12) into our machine demand equation (11), and use the result in our technology coefficient expressions (7) and (8) to get

$$
\begin{aligned}
& A_{l}=\left(\frac{1}{1-\beta}\right)^{\beta}\left(\frac{1}{\beta}\right)^{1-\beta} Q_{l}^{\beta} w_{l}^{1-\beta}, \\
& A_{h}=\left(\frac{1}{1-\beta}\right)^{\beta}\left(\frac{1}{\beta}\right)^{1-\beta} Q_{h}^{\beta} w_{h}^{1-\beta} .
\end{aligned}
$$

We plug these into the value expressions (13) and (14). After simplifying a bit, we get

$$
\begin{gathered}
V_{l}=\Psi\left(\frac{1}{Q_{l}}\right)\left(\frac{1-\beta}{\beta}\right) w_{l} L, \\
V_{h}=\Psi\left(\frac{1}{Q_{h}}\right)\left(\frac{1-\beta}{\beta}\right) w_{h} H .
\end{gathered}
$$

Computing the ratio of these last two expressions, we see that our condition for innovation to occur first in the $L$ sector is

$$
V_{h}<V_{l} \Longleftrightarrow \frac{V_{h}}{V_{l}}<1 \Longleftrightarrow \frac{V_{h}}{V_{l}}=\frac{w_{h} H}{w_{l} L}<1,
$$

given the maintained assumption that $Q_{l}=Q_{h}$.

From this we can see that the relative gains for the innovator are larger when the factor capable of using the innovation is large (the "market-size" effect) and when the price of the factor is large (the "price" effect). To get everything in terms of relative factor supplies, we can use (4), (20) and (21), to get a new expression for relative wages:

$$
\frac{w_{h}}{w_{l}}=\left(\frac{L}{H}\right)^{\frac{1}{\sigma}}\left(\frac{A_{h}}{A_{l}}\right)^{\frac{\sigma-1}{\sigma}}=\left(\frac{L}{H}\right)^{\frac{1}{(1-\beta)(1-\sigma)+\sigma}}\left(\frac{Q_{h}}{Q_{l}}\right)^{\frac{\beta(\sigma-1)}{(1-\beta)(1-\sigma)+\sigma}}
$$

Finally, by plugging this relative wage into the above inequality, and again using the 
fact that $Q_{l}=Q_{h}$, and then simplifying, we have

$$
\frac{V_{h}}{V_{l}}=\frac{w_{h} H}{w_{l} L}=\left(\frac{L}{H}\right)^{\frac{(1-\beta)(\sigma-1)-\sigma+1}{(1-\beta)(1-\sigma)+\sigma}}<1 .
$$

Given that $L / H>1$, this inequality can only hold if the exponent is negative, which (since $0<\beta<1$ ) is true only when $\sigma>1$.

In other words, provided that labor types are grossly substitutable, the initial stages of industrialization had to be unskilled-labor-intensive simply because there were so many more unskilled laborers in the workforce than skilled laborers. So, to grossly simplify the history of innovation, we maintain that for most of human existence the inequalities $\pi_{l}<0$ and $\pi_{h}<0$ held strictly. Once $\pi_{l} \geq 0$, industrialization could occur. Once both $\pi_{l} \geq 0$ and $\pi_{h} \geq 0$, robust modern economic growth could occur. As we will suggest below, this sequence was precisely how we believe history played out.

\subsection{Endogenous Demography}

With the dynamics of technology defined, we close the model by specifying the dynamics of endowments. Here we adopt a variant of a fairly standard overlapping generations model of demography suited to unified growth theory (cf. Galor and Weil 2000).

In a very simplified specification, we assume that 'adult' agents maximize their utility, which depends both on their current household consumption and on their children's expected future income. In an abstraction of family life, we assume that individuals begin life naturally as unskilled workers, accumulate human capital, and then employ that human capital as adults. An agent begins in the first period of life as an unskilled worker; as an adult in the second period of life she is a skilled worker (supplying whatever human capital she accumulated as a child). Thus her welfare will be affected by both types of wages; and given these wages, her adult income will be higher, the higher is her endowment of human capital.

Only 'adults' are allowed to make any decisions regarding demography. Specifically, the representative household is run by an adult who decides two things: how many children to have (denoted $n_{t}$ ) and the level of education each child is to receive (denoted $e_{t}$ ). The number of children must be nonnegative and to keep things simple all households are single-parent, with $n=1$ being the replacement level of fertility. The education level is constrained to the unit interval, $e \in[0,1]$, and is the fraction of time the adult devotes to educating the young. 
Our modeling of demography is as follows. An individual born at time $t$ spends fraction $e_{t}$ of her time in school (chosen by her parent), while spending the rest of her time as an unskilled laborer. At $t+1$, the individual (who is by this time a mature adult) uses whatever human capital she had accumulated as a child.

\section{The Adult Household Planner}

Allowing for the costs of child-rearing, we assume that the household consumes all the income that the family members have generated. At time $t$ there are popt adults, each of whom is an individual household planner. These planners wish to maximize the sum of current household consumption and the future skilled income generated by their children. That is, the representative agent born at time $t-1$, who is now an adult at time $t$, faces the problem

$$
\max \left\{\log \left(c_{t}\right)+\log \left(w_{h, t} n_{t} h_{t+1}\right)\right\},
$$

where $c_{t}$ is current consumption per household, $n_{t}$ is the fertility rate, and $h_{t+1}$ is each child's level of education. Note that here we assume that agents base their expectations of future wages $w_{h, t+1}$ on current wages $w_{h, t}$ in myopic fashion.

We assume a simple education technology to map time input $e$ to human capital $h$ :

$$
h_{t}=\Omega e_{t-1}^{k} \text {, }
$$

where $\Omega>0$ and $k>1$. Crucially, this equation embodies increasing returns to the input $e$, a plausible assumption in low-to-medium schooling environments. ${ }^{5}$

We now must specify more precisely how household consumption, and the endowments of unskilled and skilled labor, are functions of rates of fertility $\left(n_{t}\right)$ and education $\left(e_{t}\right)$. These variables are related to each other via the following budget constraints and

\footnotetext{
5 Prados de la Escosura (2012) provides evidence that cognitive skills increase more than proportionally as the quantity of education increases. In the returns-to-education literature, the interest is generally in estimating a constant marginal return to years of schooling, but even so some nonlinearities appear to be present, and influential works such as Card and Kreuger (1992) and Heckman et al. (2008) could be read in this way. For specific examples of estimates which find increasing returns to years of schooling consistent with our $k>1$ assumption, we refer the reader to the work of Trostel (2004, 2005). Using the Mincer regression method, this work finds OECD cross-country evidence of increasing returns to years of schooling in the elementary-middle school phase, which possibly then revert to constant or decreasing returns during high-school college; the results appear stronger in a sample that also includes middle- and low-income economies where there is on average less schooling, and it is these latter findings that might be most comparable to the nineteenth century conditions we have in mind here.
} 
assumed production relations:

$$
\begin{gathered}
c_{t}=w_{h, t} h_{t}\left(1-\tau n_{t}-x_{1} n_{t} e_{t}\right)+w_{l, t}\left[\left(1-e_{t}\right) n_{t}\right]-x_{2} n_{t} e_{t}, \\
L_{t}=n_{t}\left(1-e_{t}\right) p o p_{t}, \\
H_{t}=\Omega e_{t-1}^{k}\left(1-\tau n_{t}-x_{1} n_{t} e_{t}\right) p o p_{t},
\end{gathered}
$$

where $0 \leq \tau \leq 1,0 \leq x_{1} \leq 1$, and $x_{2} \geq 0$. The first term in (27) is the skilled income generated by the parent minus the parent's opportunity cost of child-rearing and education. The second term in (27) is unskilled income from the children who spend $1-e$ of their childhood as unskilled workers. Thus we see that when children are not being educated for a fraction of time $1-e$, they increase the family's unskilled income, but this will reduce their own future skilled income because they will receive a lower endowment of $H$ for use in the next period when they grow up. The final term in (27) is the resource costs of the childens' education.

Note that while having more children involves only an opportunity cost of time $\tau$ per child (which is duly multiplied by the skilled wages of the parent), each unit of education per child involves both an opportunity cost (captured by $x_{1}$ ) and a resource cost (of some amount $x_{2}$ ). The first of these effects is now totally standard. Having more children typically requires parents to spend more time on child rearing, and having educated children requires more time still. The second of these effects reflects the costs of educating the offspring to make them more skilled. It is also increasing in the number of children. That property appears, for example, in Galor and Mountford (2008), where, under a discrete choice, unskilled or skilled offspring may be created at exogenously fixed time $\operatorname{costs} \tau_{u}$ and $\tau_{s}$, where the latter exceeds the former (generating an exogenous, fixed skill premium on the supply side when both types of offspring are present).

Our set up is slightly different in that we have both time and resource costs in education per child. We treat both $x_{1}$ and $x_{2}$ as exogenous unit costs. In principle these might shift in response to changes in school productivity, input costs, or public policies that subsidize the cost of education. As long as the education cost contains some non-wage elements, and is therefore not linear in $w_{h}$, the general assumption that higher wages will lead to more affordable education will be preserved.

Public education policies played an increasing role in Britain towards the end of the nineteenth century, and that story and its political economy origins are discussed in Galor and Moav (2006). Although we do not examine the effects of shifts in $x_{2}$ in this paper, the presence of this term generates sharp income effects which are important for 
our account of the growth process, as for a given level of $x_{2}$, growth implies increased affordability of education. Allowing $x_{2}$ to fall would $a$ fortiori encourage a switch towards skill-biased growth, further enhancing our story. For the purposes of being conservative, and since this effect has been explored elsewhere, we keep $x_{2}$ constant.

There is no doubt but that educational costs were high relative to working class incomes in the early 19th century, and that they imposed a binding constraint on the ability of many families to educate their children. Humphries (2010, Chapter 10) provides many examples of children who were prevented from attending school because of the costs involved. School fees could be as high as 18 pence ( 1.5 shillings) per week. This compared with average weekly wages of 9 shillings and 7 pence in agriculture in 1824, or wages of the order of 20 shillings per week in the textile industry. In addition, there were costs of materials - a copy book might cost a shilling, while some schools might insist on suitable clothes. All this was enough to deter many families, especially when taken together with the opportunity costs of childrens' time. From the mid-century on, however, adult wages were rising: by the 1890 o weekly wages were over 13 shillings in agriculture, and of the other of 30 shillings in the textile industry (Bowley 1898, 1902).

The income-elasticity of education is a potentially important effect in this period, despite its omission from prevailing theories. For example, as noted by Mitch (1982, 1992), influential historians such as Schofield (1973) and West (1975), who might not agree on broader questions, thought rising incomes were important causally, allowing poorer families (with no access to credit) to be able to afford human capital investments. In his own empirical analysis, Mitch (1992, 84-86) finds mixed support for the hypothesis. ${ }^{6}$ Humphries (2010) finds that boys who were lucky enough to have access to free or subsidized schools remained in education for 14 months longer than those whose parents had to pay full fees, suggesting that the costs of education mattered for schooling choices. Similarly, while the sons of casual laborers received less education than the

\footnotetext{
${ }^{6}$ Strong results on schooling (parental income elasticities near 1) emerge from raw data, but not for regressions that include "regional" dummies (e.g., village or county), suggesting that these effects are most clearly visible across locales. In regressions of child literacy on income, regressions for specific towns (London, Macclesfield, Hanley) were unable to detect within-town variation (p. 86). But a national sample using occupational proxies for wages found an parental income elasticity of literacy of 0.72 . This last result could be undermined by the inclusion of parental literacy, but the latter is of course highly collinear with income. Mitch also found that income elasticities were falling as incomes rose, suggesting the possibility of threshold effects. In accounts by contemporaries, poor parents themselves were found to cite poverty as the main reason they did not send their kids to school, although their upper-class neighbors were apt to disagree. For the United States, Go (2008) finds a strong correlation between father's wealth and school attendance by the child in 1850; this correlation disappears in later years after the introduction of free public schools. Go and Lindert (2010) suggest that one of the main reasons why school enrollments in the U.S. North were higher than those in the U.S. South was the fact that the northern schools had lower direct costs relative to income.
} 
average boy, sons of tradesmen or service providers (who were comparatively well-off) received more.

Finally, on the equations defining factor endowments, (28) reflects the idea that only children work as unskilled laborers. (29) illustrates the usable human capital in the economy. This is the total stock of human capital after reflecting the opportunity cost for parents in child-rearing and educating their children. We note that, in this setup, increases in fertility rates will immediately translate into increased levels of unskilled labor, while increases in education will eventually translate into increased levels of skilled labor next period. Thus given our discussion above, wage changes will immediately change the overall population level, and will eventually change the level of human capital in the economy.

Given (27), the individual born at $t-1$ will choose a pair of $\left\{n_{t}, e_{t}\right\}$ that maximizes (25), taking perceived wages as given. The first-order condition for the number of children is:

$$
w_{l, t}\left(1-e_{t}\right)+\frac{c_{t}}{n_{t}}=w_{h, t} h_{t}\left(\tau+x_{1} e_{t}\right)+x_{2} e_{t} .
$$

The left-hand side illustrates the marginal benefit of an additional child, while the righthand side denotes the marginal cost. At the optimum, the gains from an extra unskilled worker in the family and more skilled income for children in the future precisely offsets the opportunity and resource costs resulting from additional child-rearing.

The first order condition for education is:

$$
c_{t} \frac{k}{e_{t}}=\left(w_{l, t}+w_{h, t} h_{t} x_{1}+x_{2}\right) n_{t} .
$$

Again the left-hand side is the marginal benefit and the right-hand side is the marginal cost, this time of an extra unit of education per child. At the optimum, the gains received from more skilled income by children offset the foregone unskilled-labor income and the extra time and resource costs associated with an extra educational unit for all children at $t$.

\section{A Tale of Two Revolutions}

Sections 1.1 and 1.2 summarize the long-run co-evolution of factors and technologies in the model. Once innovation occurs and levels of $Q_{l}$ and $Q_{h}$ are determined, the complete general equilibrium can be characterized by simultaneously solving (2), (3), (20), (21), (28), (29), (30) and (31) for wages, productivity-levels, fertility, education, and 
factor supplies.

We are now ready to see how well our model can account for what happened in England (and other northwestern European economies) in the eighteenth and nineteenth centuries.

\subsection{The Industrial Revolution}

An economy before its launch into the Industrial Revolution may be described by the features discussed in section 1.1, only with technological coefficients $A_{l}$ and $A_{h}$ constant. Here wages are fixed, and thus the levels of raw labor and human capital remain fixed as well. Both output and output per capita remain stagnant. Baconian knowledge $B$ is low. 7

If we assume that the evolution of technological coefficients $A_{l}$ and $A_{h}$ are described by the relationships in section 1.1, then the economy must wait until Baconian knowledge grows to a sufficient level before applied innovation becomes possible. Further, technological growth will initially be unskilled-labor biased (that is, there is growth in $A_{l}$ ) so long as it becomes profitable to improve machines used in the unskilled sector before it becomes profitable to improve machines used in the skilled sector. Thus if the economy begins such that $Q_{l}=Q_{h}$ (as we maintain in the simulations that follow), initial technological growth will be unskilled labor biased so long as there is relatively more unskilled labor than skilled labor in the economy (by Proposition 1), as was surely the case in the eighteenth century.

Next, the onset of technological developments changes the wage structure, and by implication the evolution of factor endowments. The growth of $A_{l}$ lowers the skill premium, as can be seen in our expression (4), increasing the future ratio of unskilled wages to skilled wages. As $w_{l}$ rises faster than $w_{h}$, the marginal gains of having more children (the left hand side of equation 30) rise faster than the marginal costs (the right hand side of 30); households respond by raising fertility.

This story of unbalanced growth in early industrialization seems consistent with history. Well-known studies such as Atack (1987) and Sokoloff (1984) describe the transition of the American economy from reliance on highly-skilled artisans to the widespread

\footnotetext{
${ }^{7}$ Although not Malthusian in nature, the initial static phase in our model is broadly consistent with Malthusian dynamics in the following way. If we consider the pre-Industrial world, one where $L$ is much larger than $H$, and maintain the assumption that these factors are grossly substitutable, then any technological change that could have a meaningful influence on average incomes would necessarily be unskilled-labor biased. As the model demonstrates, this will induce a rise in fertility and influence education only modestly. Thus, our model is entirely consistent with the pre-Industrial correlation between brief and temporary bursts of technologically-induced income gains and increases in population.
} 
mechanization of factories. This paper further argues that the boom in fertility that the industrializing areas experienced was both the cause and consequence of these technological revolutions arising, in the British case, in the late 1700 and early 1800 . According to Folbre (1994), the development of industry in the late eighteenth and early nineteenth centuries led to changes in family and household strategies. The early pattern of rural and urban industrialization in this period meant that children could be employed in factories at quite a young age. The implication is that children became an asset, whose labor could be used by parents to contribute income to the household. In English textile factories in 1835 , for example, $63 \%$ of the work force consisted of children aged 8-12 and women (Nardinelli 1990). This is not to say that attitudes toward children were vastly different in England then compared with now; rather economic incentives were vastly different then compared with now (Horrell and Humphries 1995). As a result of these conditions, fertility rates increased during the period of early industrialization.

Thus our approach may help explain the population growth that coincided with the initial stages of the Industrial Revolution. ${ }^{8}$ However, we are still faced with the challenge of explaining the demographic transition that followed it.

\subsection{The Demographic Transition}

Figure 2 documented rising education and falling fertility rates in four advanced countriesbut only late in the 19th century-a shift which was replicated in many rich countries at the time. Part of our argument is that biases inherent in technological innovation fostered this reversal. As Baconian knowledge rose further and skill-biased production grew in importance, the labor of children became less important as a source of family income, and this was reflected in economic behavior. It is true that legislation limited the employment possibilities for children (Folbre 1994), and introduced compulsory education. However,the underlying economic incentives were leading in the same direction.

The incentives for households to reverse fertility trends and dramatically expand education came about through changes in wages. As evident from (30) and (31), households will want to invest in greater education and limit fertility not only when skilled wages rise relative to unskilled wages (since educated children provide a greater relative return than unskilled children), but also when overall wages rise (since the resource costs of education grow less onerous with wage growth).

Modest wage growth and falling relative returns to skilled labor, characteristic of

\footnotetext{
${ }^{8}$ Of course there are a host of other explanations, including falling death rates related to health improvements, and the passage of various Poor Laws. Naturally we are abstracting from these possibilities without dismissing them as inconsequential.
} 
early industrialization, allows fertility to rise while keeping education growth modest. But once overall wages have risen sufficiently, the benefits of education begin to dramatically outweigh the costs, and the transition in household demand from child quantity to child quality is truly launched. ${ }^{9}$

\subsection{Simulations}

How well does our theoretical model track these general historical trends? To answer this we numerically simulate the model.

For each time period, we solve the model as follows:

(1) Baconian knowledge $B$ grows according to equation (17).

(2) Based on this new level of Baconian knowledge $B$, if $\pi_{l}>0$, then $Q_{l}$ rises by a factor of $\varepsilon$; and if not, $Q_{l}$ remains the same. Similarly, if $\pi_{h}>0, Q_{h}$ rises by a factor of $\varepsilon$; and if not, $Q_{h}$ remains the same. ${ }^{10}$

(3) Given levels of $Q_{l}$ and $Q_{h}$, we solve for equilibrium using the system of equations (2), (3), (20), (21), (28), (29), (30) and (31) for $w_{l}, w_{h}, A_{l}, A_{h}, n, e, L$, and $H$.

In our baseline case, parameters are set equal to the following: $\sigma=2, \beta=0.65$, $\alpha=1.5, \varepsilon=1.05, \phi=2, \Omega=5, k=1.5, \tau=0.43, x_{1}=0.5, x_{2}=0.5$. Choice of parameter values stem from a number of motivations. $\sigma=2$ complies with most studies analyzing the degree of substitutability between skilled and unskilled workers. ${ }^{11}$ $\beta$ and $\varepsilon$ are chosen to ensure that quality improvements for machines are large enough to maintain monopoly pricing (see Appendix 1 ). $\alpha$ (the "fishing-out" parameter) is chosen to keep research costs from rising too fast to prevent on-going innovations (see Appendix 2 where we relax this).

\footnotetext{
${ }^{9}$ Recent studies make a variety of related points which can also explain the demographic transition. Hazan and Berdugo (2002) suggest that technological change at this stage of development increased the wage differential between parental labor and child labor, inducing parents to reduce the number of their children and to further invest in their quality, stimulating human capital formation, a demographic transition, and a shift to a state of sustained economic growth. In contrast, Doepke (2004) stresses the regulation of child labor. Alternatively, the rise in the importance of human capital in the production process may have induced industrialists to support laws that abolished child labor, inducing a reduction in child labor and stimulating human capital formation and a demographic transition (Doepke and Zilibotti 2003; Galor and Moav 2006; Galor 2012).

${ }^{10} \mathrm{We}$ can relax this assumption to allow for multiple-step quality improvements each period. Simulation results (not shown) display the same patterns for fertility, education, and relative wages as our main results.

${ }^{11}$ The degree of substitutability between skilled and unskilled labor has been much explored by labor economists. Studies of contemporary labor markets in the U.S. (Katz and Murphy 1992, Peri 2004), Canada (Murphy et al. 1998), Britain (Schmitt 1995), Sweden (Edin and Holmlund 1995), and the Netherlands (Teulings 1995) suggest aggregate elasticities of substitution in the range of one to three. See Katz and Autor (1999) for a detailed review of this literature.
} 
The parameters $\Omega, k, \tau$, and $x_{1}$ together determine the stock of human capital in the economy. We jointly choose values for these so that $H<L$ and the skill premium begins at a reasonable value of around 1.7. Of course many other combination of values would produce this. Past studies provide us little guidance as to what the "proper" combination of values should be, so we explore other various combinations of values in Appendix 2.

Many other parameterizations will produce qualitatively similar results, and we shall explore this in some sensitivity analysis that follows below and in Appendix 2; for now we focus on our baseline simulation. The critical assumptions here are that $\sigma>1$ (the skilled- and unskilled-labor-intensive intermediates have enough substitutability to satisfy Proposition 1) and $x_{2}>0$ (positive resource cost to raising educated children). ${ }^{12}$

In choosing our initial equilibrium conditions, we set $n_{1}=1.1$ (to capture the positive population growth rate experienced in Britain in the mid-18th century, before the onset of the Industrial Revolution), and $p_{0} p_{1}=1 .{ }^{13}$ We then solve the $9 \times 9$ system of (2), (3), (20), (21), (28), (29), (30), (31), and an expression for $Q_{l}=Q_{h}$ for initial values of $w_{l}, w_{h}$, $A_{l}, A_{h}, L, H, e, Q_{l}$, and $Q_{h}{ }^{14}$ Given $Q_{l}=Q_{h}$ and ensuring that $w_{h} / w_{l}>1$, it must be that $L>H$. By Proposition 1 , this implies that the first stage of the Industrial Revolution must be unskilled in nature. To see this we turn to modeling the economy as it evolves in time.

We simulate our hypothetical northwestern European economy through to time periods, where each "period" corresponds to about say 20 years of real time. We are thus roughly accounting for the time period 1710-1910. The results are given in Figures 3 through 8 , using the parameterizations summarized above. ${ }^{15}$

Figure 3 illustrates the market for innovation. Initial Baconian knowledge $B$ is set low enough that the costs of innovation are larger than the benefits in the beginning. As a result technology levels remain stagnant at first. But through Baconian knowledge growth costs fall, first catching up with the benefits of research for technologies designed for unskilled labor; hence, at $t=3$, we see that $Q_{l}$ begins to grow (that is, $\pi_{l}$ becomes positive). By contrast, $\pi_{h}<0$ early on, so $Q_{h}$ remains fixed. Note that this results solely

\footnotetext{
${ }^{12}$ Other parameters simply scale variables (such as $\Omega$ ) or affect the speed of growth (such as $\alpha, \varepsilon$ and $\phi$ ). Changing the values of these parameters however would not shift the direction of technology, nor would it affect the responsiveness of households. Thus these specific values are not crucial for the qualitative results and our underlying story.

${ }^{13}$ Each period in our model is equivalent to roughly 20 years, so this is equivalent to assuming that initially population grows by about 5 per cent every to years.

${ }^{14}$ This produces initial values of $w_{l}=0.34, w_{h}=0.53, A_{l}=0.20, A_{h}=0.24, L=0.75, H=0.32$, $e=0.32, Q_{l}=Q_{h}=0.04$.

${ }^{15}$ The initial level of $B$ is chosen such that growth starts after a few periods.
} 
because $L$ is larger than $H$ through Proposition 1. In other words, endowments dictate that the Industrial Revolution will initially be unskilled-biased. As $Q_{l}$ rises the costs of subsequent unskilled innovation are pushed up because it gets increasingly more expensive to develop new technologies the further up the quality ladder we go (due to the "fishing-out" effect from the $\alpha$ term); however, research costs continue to fall from further growth in Baconian knowledge (see equation 15), and the benefits of research rise even faster due to both rising unskilled wages and unskilled labor supplies (see equation 22). As a result unskilled-intensive growth persists.

Skill-biased technologies, on the other hand, remain stagnant during this time. Their eventual growth is however inevitable; Baconian knowledge growth drives down the costs to develop them, and rising skilled wages (due to the growth of unskilled technologies) drives up the value of developing them, as seen in equation (3). By $t=6$, $\pi_{h}$ becomes positive as well, allowing $Q_{h}$ to climb. At this point growth occurs in both sectors, with advance in all periods given by the constant step size on the innovation ladders. Note that this induces an endogenous demographic transition; population growth rates begin to fall, while education rates rise, as we can see in Figures 4 and 5 .

Figures 4 through 8 depict historical and simulated time series for population growth rates, education rates, wages, skill premia and income per capita. The skill premia data are taken from Clark (2007), but we readily admit that it is difficult, if not impossible, to identify data which can unambiguously track "the skill premium" during this period. Clark's data track the relative earnings of skilled and unskilled workers over time, but one can argue that what really mattered during this period was the obsolescence of old skills, and the emergence of new skills paying new premia. ${ }^{16}$

As can be seen, our model reproduces the early rise in population growth rates, followed by falling population growth and rising education. Education rates rise very modestly during the early stages of the Industrial Revolution, and accelerate only after growth occurs in both sectors. To understand the fertility and education patterns depicted in Figures 4 and 5, one must observe the absolute and relative wage patterns depicted in Figures 6 and 7. The early stages of industrialization are associated with very limited wage growth and a flat or modestly rising skill premium. This makes sense: what growth in applied knowledge does occur is confined to the unskilled sector, but population response offsets a sharp decline in the skill premium that might otherwise occur. However, as we shall see in the robustness exercises that follow, the general patterns prevail even when we change parameters in such a way as to allow rising or declining skill premie during the early industrialization period, ensuring that our results

\footnotetext{
${ }^{16}$ Mokyr and Voth (2010) present a critique of Clark's skill premium data.
} 


\section{Figure 3: Incentives for Innovation in Each Sector}

The figure shows the value of innovating and the cost of innovating in each period for each sector in our simulated model. The economy is initially endowed with much more unskilled labor $L$ than skilled labor $H$. Hence, unskilled-intensive technologies are the first to experience directed technological change.

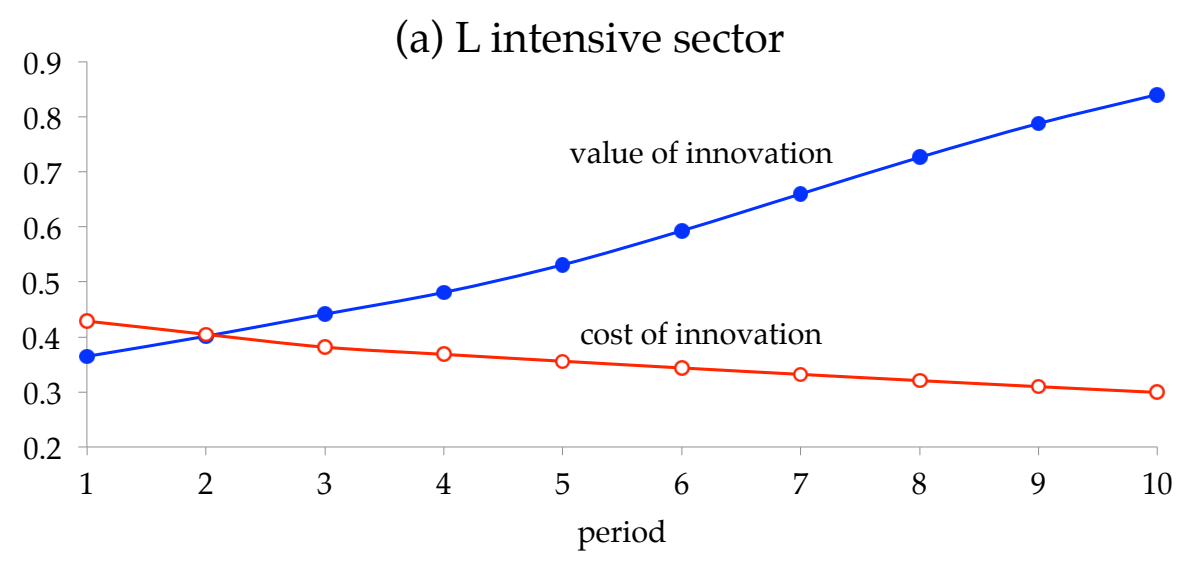

(b) H intensive sector

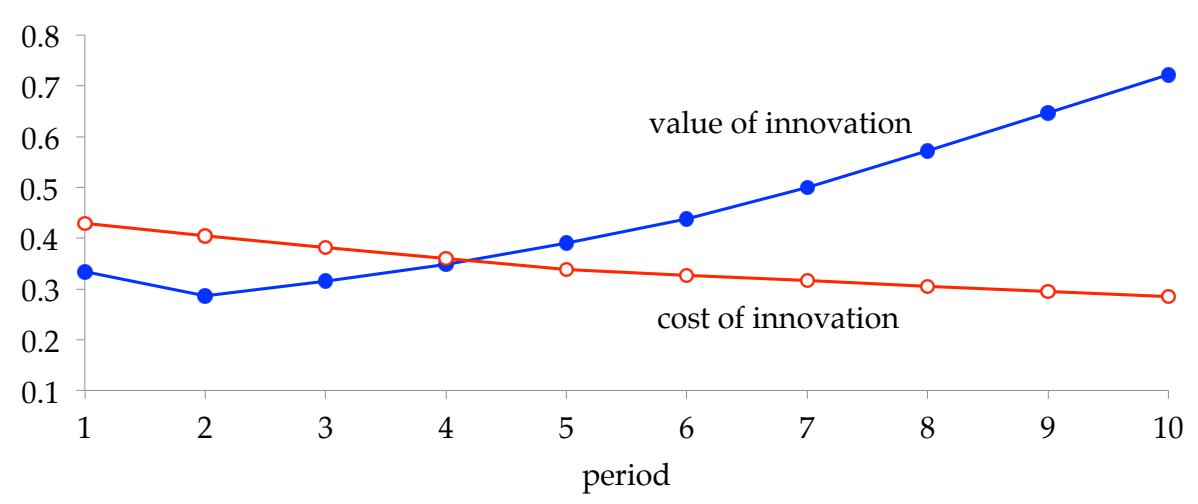

Source: See text. 
Figure 4: Population Growth Rates: Data versus Model

The figure shows the population growth rates in the English data and in the simulated model.

(a) Fertility: data (births per 1000 women)

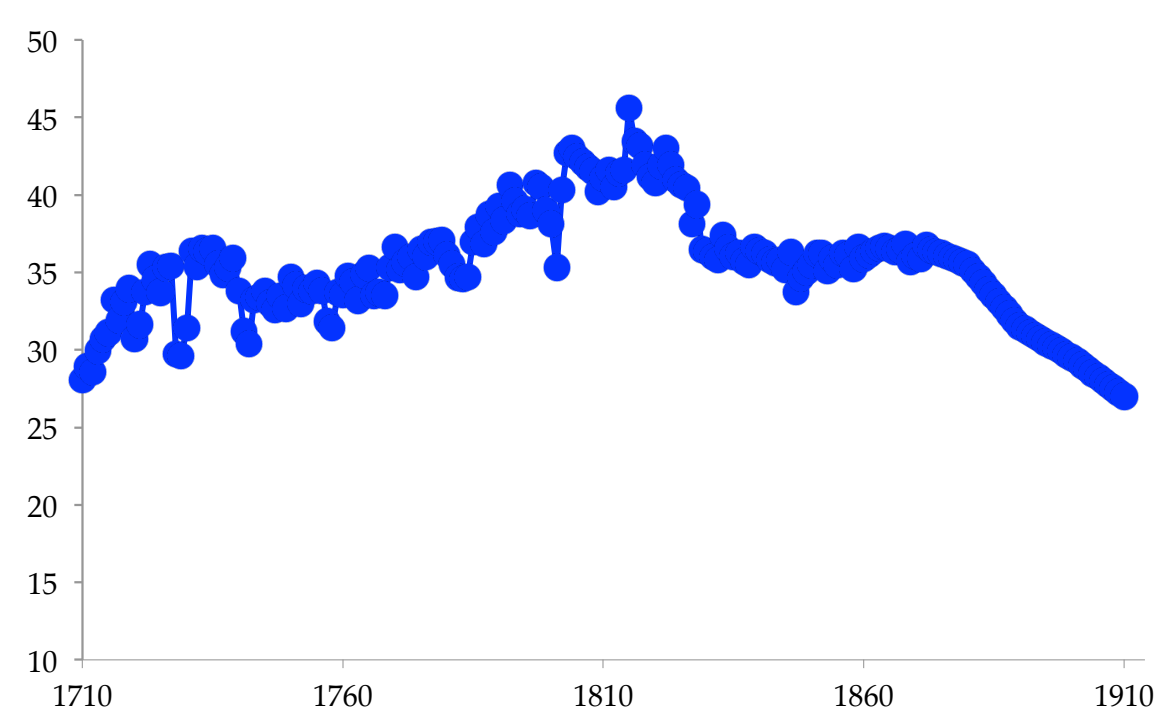

(b) Population growth rate: model (\%)

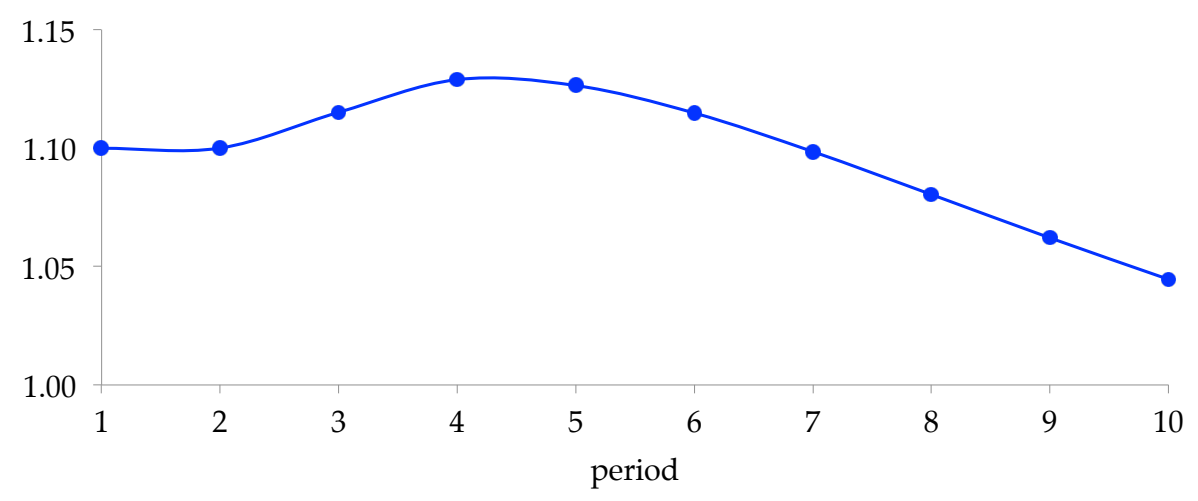

Source: England (excl. Monmouthshire) until 1801, and England and Wales thereafter, from Mitchell (1988). 


\section{Figure 5: Education: Data versus Model}

The figure shows the education levels in the English data and in the simulated model.

(a) Education: data (\% of 5-14 year olds in school)

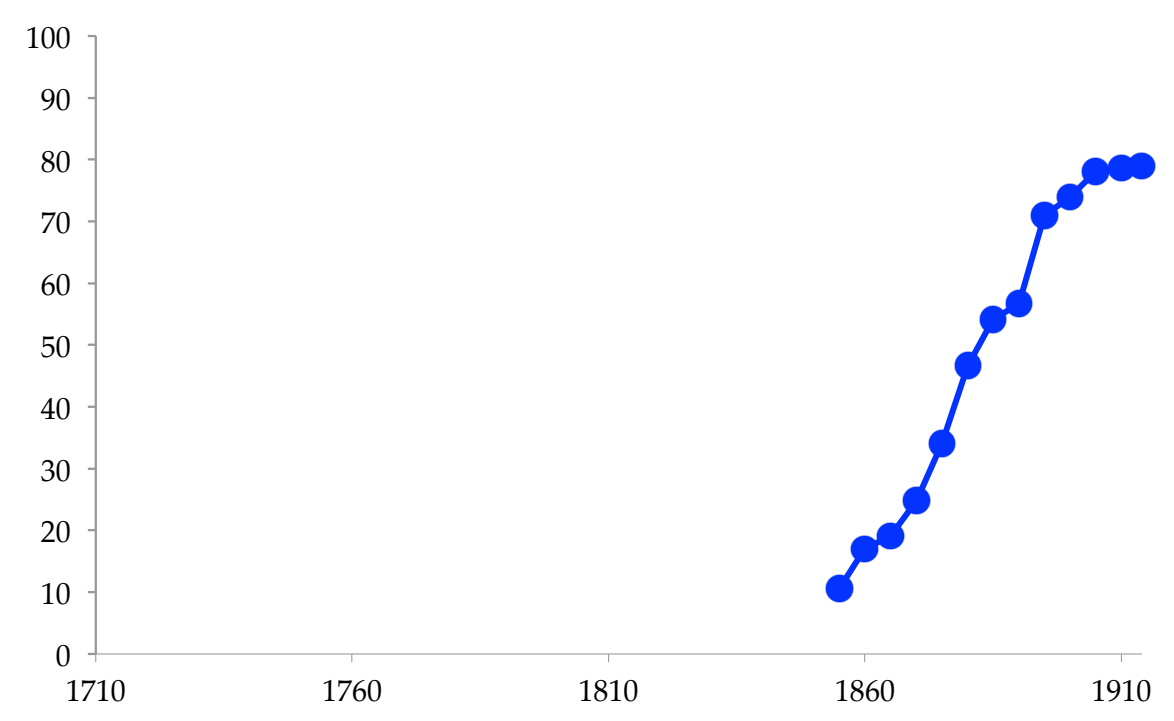

(b) Education: model

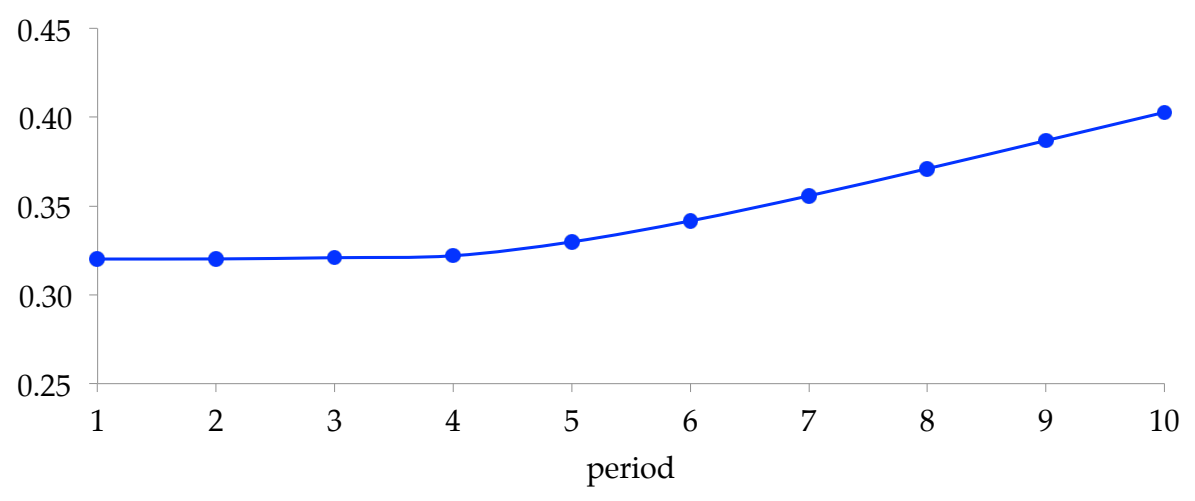

Source: Ten-year moving averages from Flora et al. (1983). 
Figure 6: Wages: Data versus Model

The figure shows wage levels in the English data and in the simulated model.

(a) Real wages: data (index)

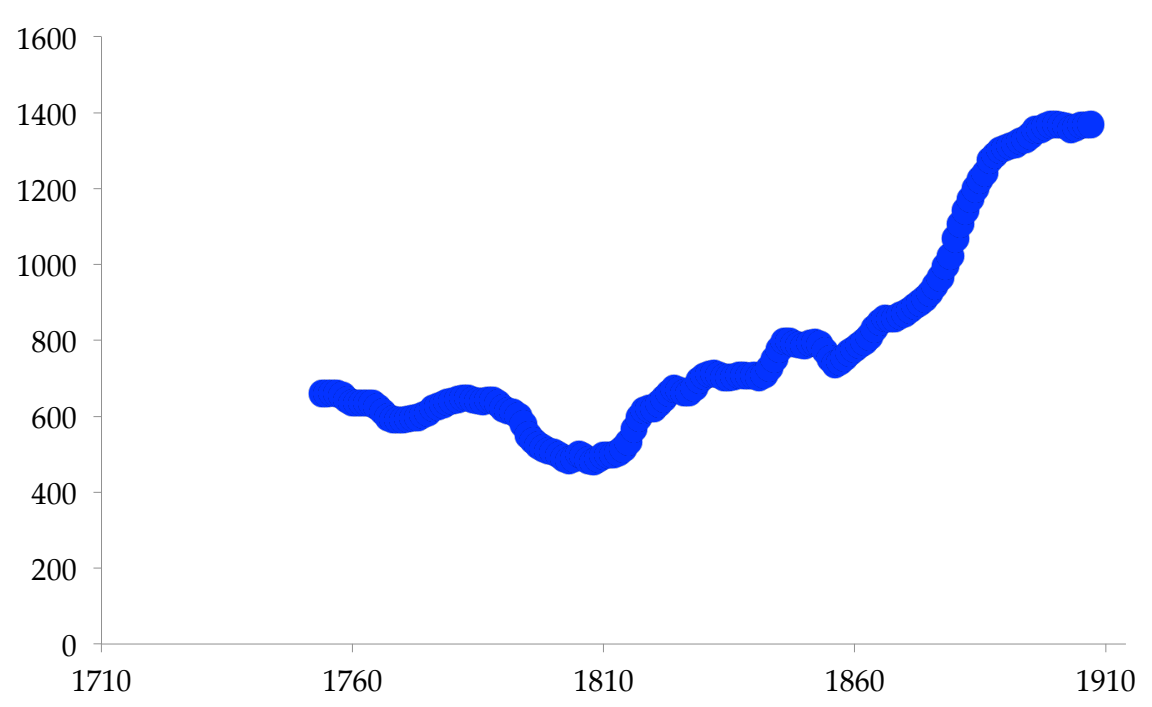

(b) Real wages: model (skilled and unskilled)

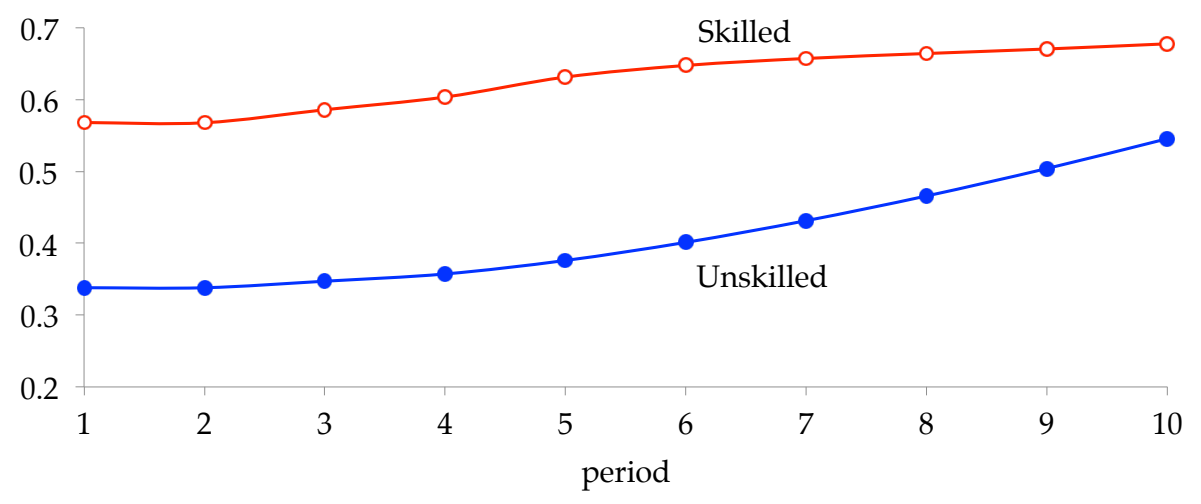

Source: Ten-year moving averages from Wrigley and Schofield (1981). 
Figure 7: Skill Premium: Data versus Model

The figure shows wage levels in the English data and in the simulated model.

(a) Skilled/ unskilled wage: data

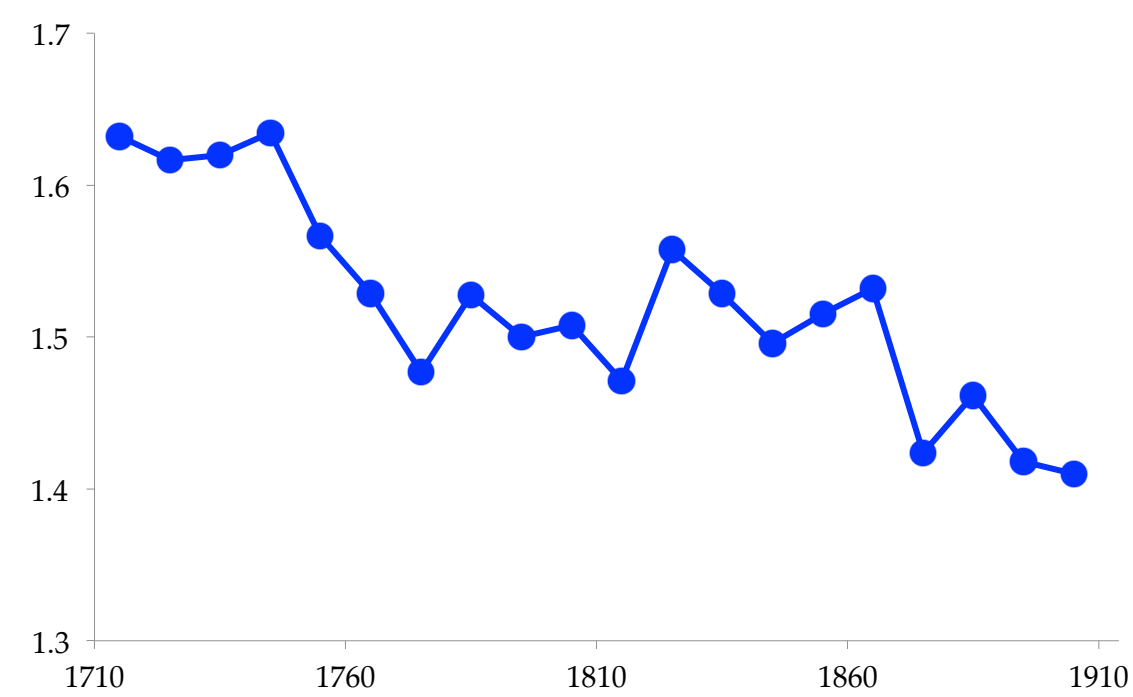

(b) Skilled/ unskilled wage: model

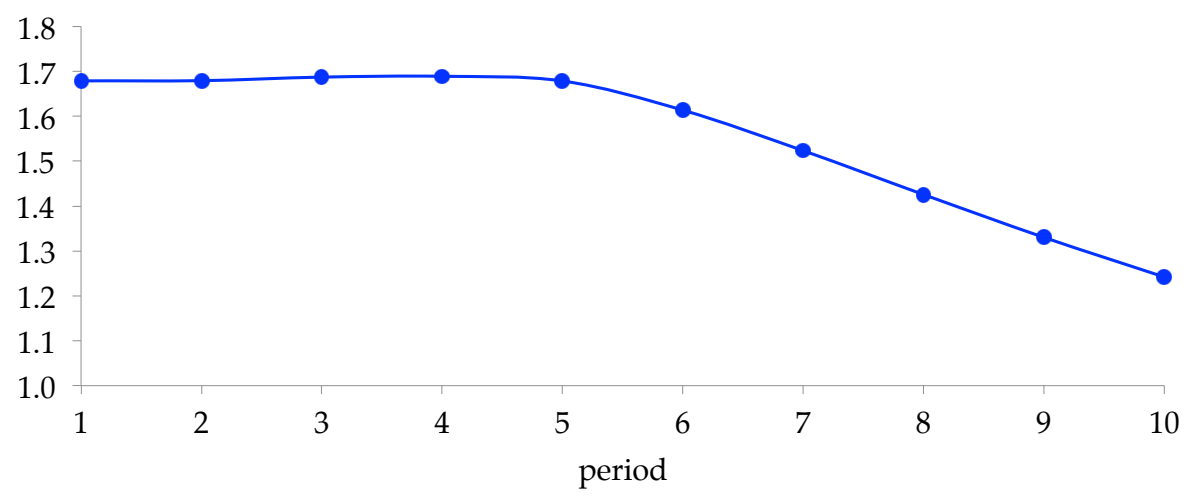

Source: Clark (2007). 
Figure 8: GDP per Person: Data versus Model

The figure shows GDP per person in the U.K. data and in the simulated model.

(a) GDP per person: data

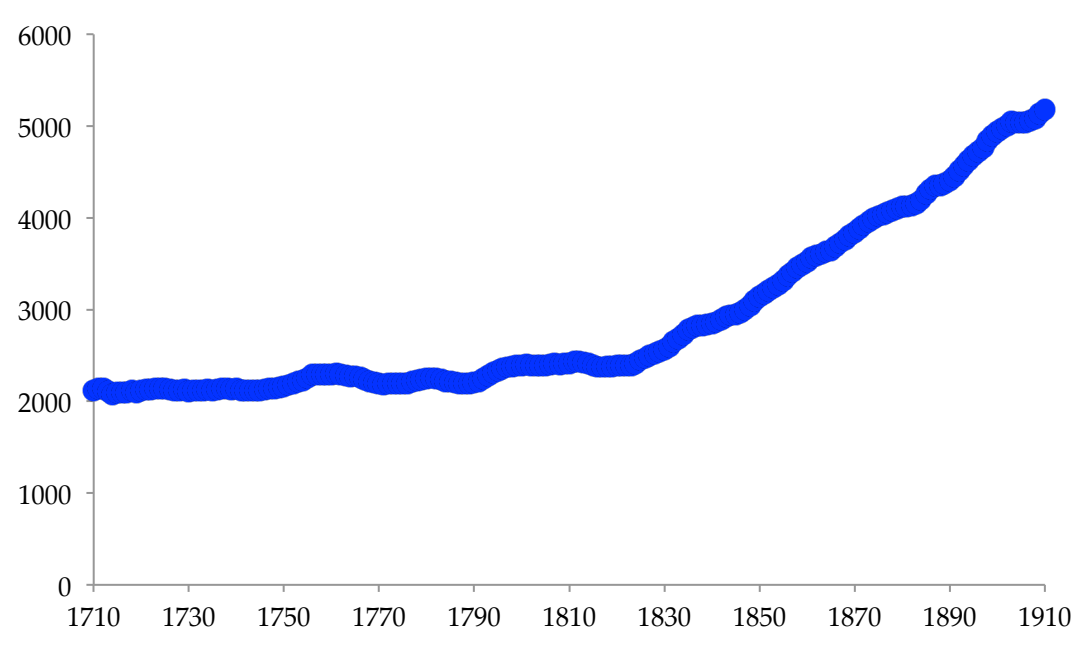

(b) GDP per person: model

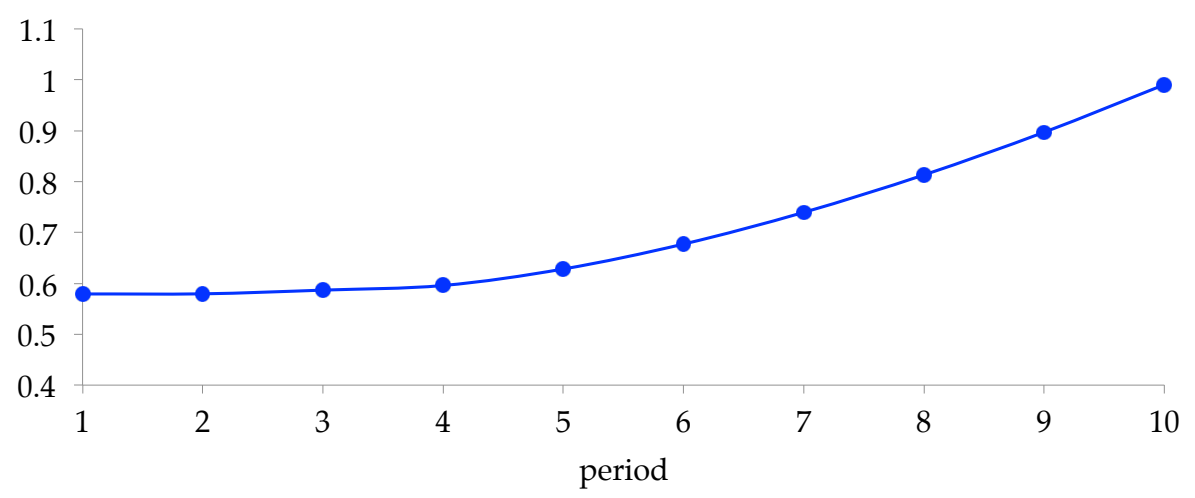

Source: Ten-year moving averages from Broadberry and van Leeuwen (2008) and Maddison (2003). 
are not hostage to particular interpretation of these contentious data series.

These countervailing forces keep growth in education during this period modest. Fertility however is free to rise: since slow-rising education keeps the resource costs of each child low, parents can take advantage of rising unskilled wages by having more children. Of course this produces more $L$ and keeps $H$ fairly low. Thus the model can replicate the rapid fertility growth and low education growth observed during the early stages of the Industrial Revolution.

Once skill-biased technologies grow as well, the patterns of development change dramatically. Growth in both $A_{l}$ and $A_{h}$ allows wages to rise more rapidly, even as the skill premium starts to fall rapidly. Education rates rise faster as education becomes more affordable. More affordable education, together with a rising opportunity cost of having children, incites adults to lower their fertility. There is thus an endogenous switch from child quantity to child quality consistent with history (Galor 2012). The demographic transition of the mid to late 19th century is launched.

Figures 3 through 8 thus depict an integrated story of western European development fairly consistent with the historical record. The theory of endogenous technical change can indeed motivate a unified growth theory. Increases in income induce increases in education, which then through the quality-quantity tradeoff eventually induce a fall in fertility. And increases in $H / L$ put downward pressure on the premium through supply-side forces. Thus, as implied by (24), continued supply increases can keep pace with demand-side forces (Goldin and Katz 2008): a modern economy can have both high relative skilled labor supplies and a low skill premium even in the context of directed endogenous technological change.

Our simulations show skill-biased technology starting to be used, and rising in importance, quite early on, even at the time of the fertility peak. This is not the same thing as saying that skill biased sectors became dominant at that point, in absolute, macro terms (although they did later on). This is the standard argument that nascent sectors start from a very low base (which was famously the case of cotton textiles, for example, during the First Industrial Revolution). They only win out in the longer run. The fact that our model incorporates both types of technological change simultaneously (rather than, say, switching in a discontinuous manner from one type of innovation to another) is, we believe, a positive feature of the paper in that it corresponds better with historical reality.

Finally, Figure 8 shows the evolution of output per person in the data and the model. In both theory and reality, the population growth spurred by initial technological growth kept per capita income growth very modest-making the 'Industrial Revolution' appear 
Figure 9: Robustness Check 1

The figure shows the model simulation when $x_{1}=1$ and $x_{2}=0.5$.
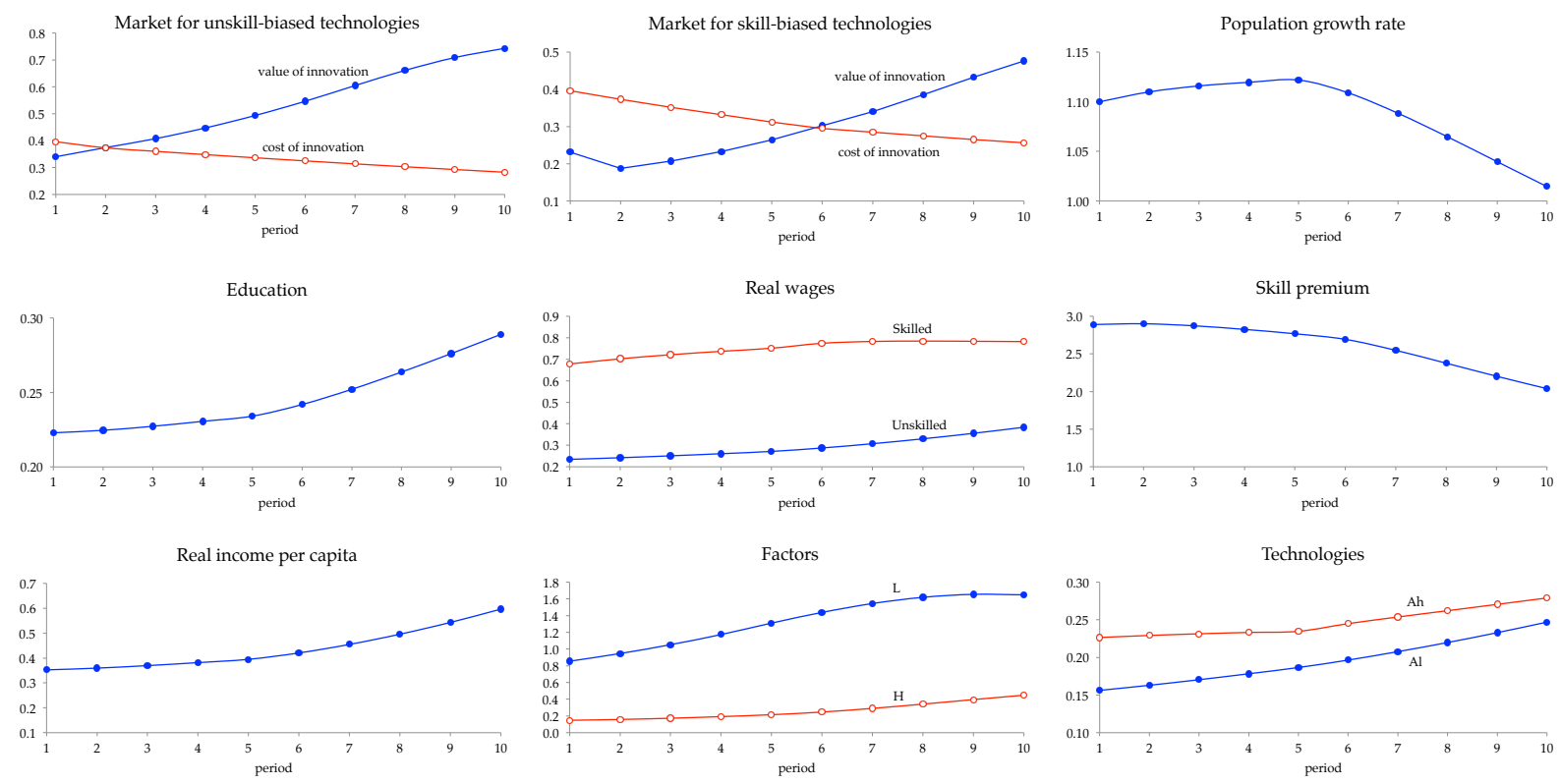

to be a fairly un-revolutionary event. But later on, with technological advance occurring in more sectors, incomes rose faster; this in turn provoked fertility decreases and made per capita growth faster still, heralding a more marked trend breakout into "modern economic growth."

\section{Robustness checks}

One might wonder if our results are sensitive to our assumed time and resource costs of child-rearing. That is, what if $x_{1}$ and/or $x_{2}$ had different values? Here we demonstrate that the patterns of industrialization implied by our model are robust to different childrearing costs.

Figure 9 illustrates the results of our simulation when we increase only the time costs $x_{1}$ to rearing educated children by a factor of two relative to the baseline. All other parameters are the same as in the baseline case, and again we set $n_{1}=1.1$ and pop $_{1}=1$. Raising time costs to education lowers the total amount of skilled labor in the economy. The implications of this are a much higher skill premium, and delayed growth in skill-intensive technologies. However, the general patterns for fertility, education, and absolute and relative wages are very similar to our baseline case. 


\section{Figure 10: Robustness Check 2}

The figure shows the model simulation when $x_{1}=0.5$ and $x_{2}=1$.
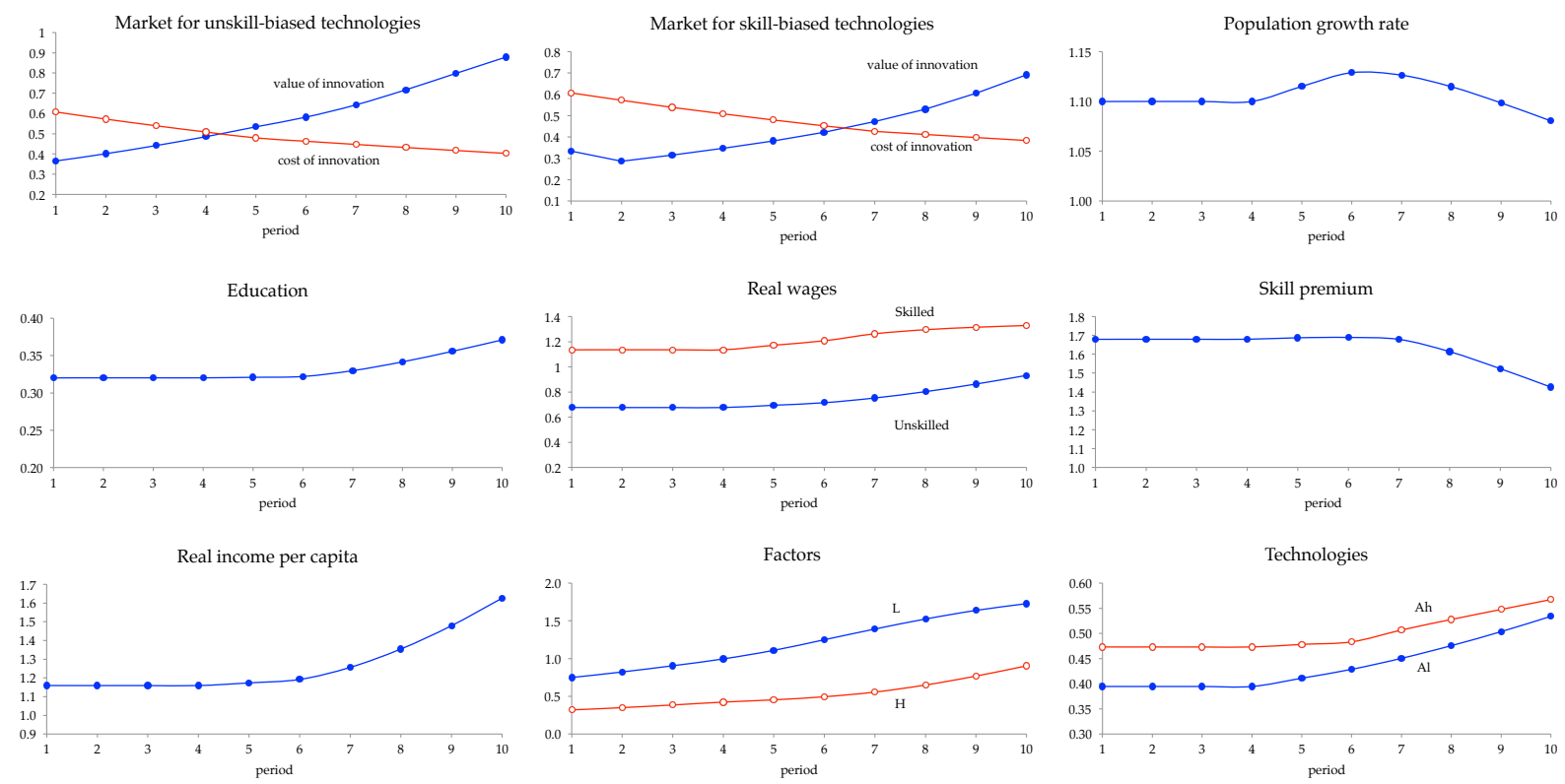

Figure 11: Robustness Check 3

The figure shows the model simulation when $x_{1}=1$ and $x_{2}=1$.
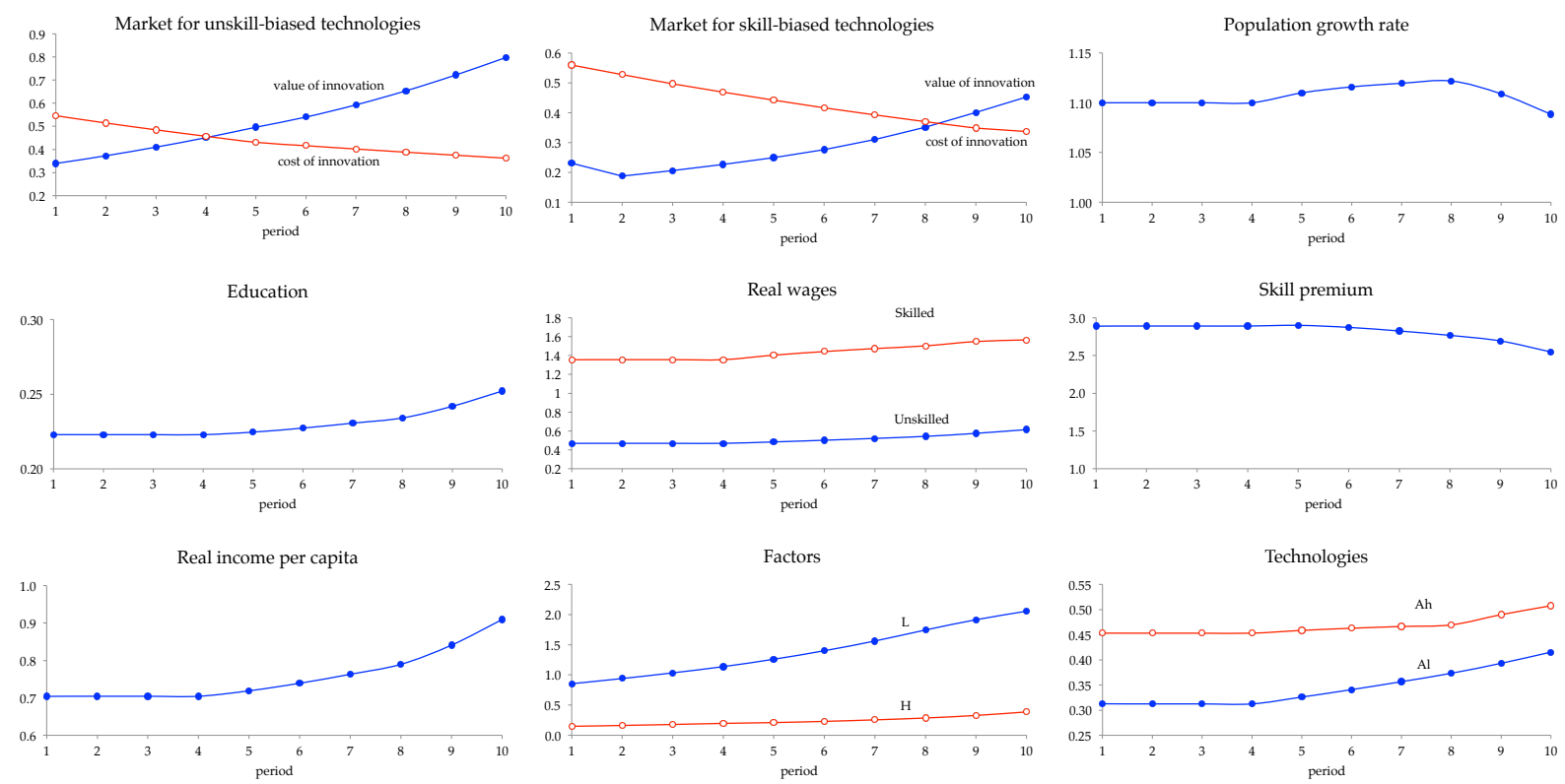
Figure 10 displays the evolution of the economy with only the resource costs to education $x_{2}$ increased by a factor of two relative to the baseline (specifically, $x_{1}$ is set back to its original value of 0.5 ). Again, patterns of fertility, education and wages echo those in the baseline case, but with some delay in economic growth. A higher resource cost to education scales up the economy (higher $x_{2}$ in equations 30 and 31 implies higher wages, implying higher technologies). Because $Q_{l}$ and $Q_{h}$ are higher, costs to innovation begin at a higher level, thus delaying the onset of technological progress. But while the timing of economic takeoff is affected, the patterns of development are not.

Finally, Figure 11 displays the case where both $x_{1}$ and $x_{2}$ are raised by a factor of two. The pattern resembles a mix of those seen in Figures 9 and 10. Again, a consistent pattern of development emerges. In general, adjusting other parameters similarly affects either the speed or the timing of growth, but not the general patterns (see appendix 2). The bottom line is that our model is able to capture the key features of industrialization given the reasonable assumptions of gross substitutability in labor-types and some resource costs for education.

\section{Conclusion}

We believe that by explicitly modeling research and development, thus endogenizing the direction of technical change, we have been able to shed some valuable light on the transition to modern economic growth. Like most unified growth models, our model is subject to the criticism that it makes a take-off "inevitable," a proposition to which many historians, more comfortable with notions of chance and contingency, might object.

Our model makes another claim, however, which seems much more robust: if a takeoff took place, it most likely should have first involved unskilled-labor-using technologies, for the simple reason that unskilled labor was the abundant factor of production at this time. Eventually, however, continuing growth in Baconian knowledge led to the growth of the science-based, skill-intensive sectors of the Second Industrial Revolution. While this could have caused skill premia to start rising, massive endogenous increases in education kept the relative wages of skilled labor in check, and actually led them to fall, at an accelerating rate.

Furthermore, in addition to these forces which are endogenous to our model, there were other factors at work keeping skill premia down. For example, Galor and Moav (2006) highlight the fact that governments embarked on a large-scale programme of public education, raising skill endowments and lowering skill premia. Furthermore, public primary education programmes were later followed by two world wars, rising union 
strength, and public secondary and tertiary education programmes, all of which served to further reduce skill premia-in the U.S. case at least through the "Great Compression" of the 1940s (Goldin and Margo 1992; Goldin and Katz 2008).

It seems possible that these factors leading to greater equality were actually endogenously influenced by growth, even though powerful endogenous technological factors were pushing economies towards greater inequality. This is striking, since as Acemoglu (1998) points out, in the context of a model like this one, long run exogenous increases in skill endowments lead to more rapid skill-biased technical change, thus increasing the upward pressure on skill premia in the long run. What is remarkable, therefore, is that western labor markets remained on an egalitarian path until well into the twentieth century. In this context, current inegalitarian trends in the U.S. and elsewhere can be seen as late nineteenth century chickens finally coming home to roost.

\section{References}

Acemoglu, Daron. 1998. Why Do New Technologies Complement Skills? Directed Technical Change and Wage Inequality. Quarterly Journal of Economics 113(4): 1055-89.

Acemoglu, Daron. 2007. Equilibrium Bias of Technology. Econometrica 75(5): 1371-1409.

Aghion, Philippe, and Peter Howitt. 1992. A Model of Growth through Creative Destruction. Econometrica 60(2): 323-51.

Allen, Robert C. 2006. The British Industrial Revolution in Global Perspective: How Commerce Created the Industrial Revolution and Modern Economic growth. Nuffield College, Oxford. Unpublished.

Allen, Robert C. 2009. The British Industrial Revolution in Global Perspective. Cambridge: Cambridge University Press.

Andorka, Rudolph. 1978. Determinants of Fertility in Advanced Societies. New York: The Free Press.

Atack, Jeremy. 1987. Economies of Scale and Efficiency Gains in the Rise of the Factory in America, 1820-1900. In Quantity and Quiddity: Essays in U.S. Economic History edited by P. Kilby. Middletown, Conn.: Wesleyan University Press, pp. 286-335.

Barro, Robert J., and Xavier Sala-i-Martin. 2003. Economic Growth. 2nd edition. Cambridge, Mass.: MIT Press.

Becker, Gary S., and H. Gregg Lewis. 1973. On the Interaction between the Quantity and Quality of Children. The Journal of Political Economy 81(2): S279-88.

Becker, Gary S., and Nigel Tomes. 1976. Child Endowments and the Quantity and Quality of Children. Journal of Political Economy 84(4): S143-62. 
Boberg-Fazlic, Nina, and Jacob Weisdorf. 2012. Human Capital Formation from Occupations: The 'Deskilling Hypothesis' Revisited. University of Southern Denmark. Unpublished.

Bowley, A. L. 1898. The Statistics of Wages in the United Kingdom During the Last Hundred Years. (Part I.) Agricultural Wages. Journal of the Royal Statistical Society 61(4): 702-22.

Bowley, A. L. 1902. The Statistics of Wages in the United Kingdom During the Last Hundred Years. (Part IX.) Wages in the Worsted and Woollen Manufactures of the West Riding of Yorkshire. Journal of the Royal Statistical Society 65(1): 102-26.

Broadberry, Stephen N., and Bas van Leeuwen. 2008. British Economic Growth and the Business Cycle, 1700-1850: Annual Estimates. University of Warwick. Unpublished.

Card, David, and Krueger, Alan B. 1992. Does School Quality Matter? Returns to Education and the Characteristics of Public Schools in the United States. Journal of Political Economy 100(1): $1-40$.

Ciccone, Antonio, and Giovanni Peri. 2005. Long-Run Substitutability Between More and Less Educated Workers: Evidence from U.S. States, 1950-1990. Review of Economics and Statistics $87(4): 652-63$.

Clark, Gregory. 1987. Why Isn't the Whole World Developed? Lessons from the Cotton Mills. Journal of Economic History 47(1): 141-73.

Clark, Gregory. 2007. A Farewell to Alms: A Brief Economic History of the World. Princeton, N.J.: Princeton University Press.

Doepke, Matthias. 2004. Accounting for Fertility Decline during the Transition to Growth. Journal of Economic Growth 9 (September): 347-83.

Doepke, Matthias, and Fabrizio Zilibotti. 2003. Voting with your Children: A Positive Analysis of Child Labour Laws. CEPR Discussion Papers no. 3733.

Edin, Per Anders, and Bertil Holmlund. 1995. The Swedish Wage Structure: The Rise and Fall of Solidarity Wage Policy? In Differences and Changes in Wage Structures, edited by R. Freeman and L. Katz. Chicago: University of Chicago Press and NBER, pp. 307-44.

Flora, Peter, Jens Alber, Richard Eichenberg, Jürgen Kohl, Franz Kraus, Winfried Pfenning, and Kurt Seebohm. 1983. State, Economy, and Society in Western Europe, 1815-1975: A Data Handbook in Two Volumes, volume I, The Growth of Mass Democracies and Welfare States. Frankfurt am Main, Germany: Campus Verlag.

Folbre, Nancy. 1994. Who Pays for the Kids? Gender and the Structure of Constraint. New York: Routledge.

Galor, Oded. 2005. From Stagnation to Growth: Unified Growth Theory. In Handbook of Economic Growth, volume 1, part 1, edited by P. Aghion and S. N. Durlauf. Amsterdam: North Holland, pp. 171-293.

Galor, Oded. 2011. Unified Growth Theory. Princeton, N.J.: Princeton University Press.

Galor, Oded. 2012. The Demographic Transition: Causes and Consequences. Cliometrica 6(1): $1-28$. 
Galor, Oded, and Omer Moav. 2002. Natural Selection and the Origin of Economic Growth. Quarterly Journal of Economics 117(4): 1133-91.

Galor, Oded, and Omer Moav. 2006. Das Human-Kapital: A Theory of the Demise of the Class Structure. Review of Economic Studies 73(1): 85-117.

Galor, Oded, and Andrew Mountford. 2008. Trading Population for Productivity. Review of Economic Studies 75(4): 1143-79.

Galor, Oded, and David Weil. 2000. Population, Technology and Growth: From Malthusian Stagnation to the Demographic Transition and Beyond. American Economic Review 90(4): 80628.

Go, Sun. 2008. Schools in America, 1850-1870: Who Voted for Them, Who Got Them, and Who Paid. UC Davis. Unpublished.

Go, Sun, and Peter Lindert. 2010. The Uneven Rise of American Public Schools to 1850. Journal of Economic History 70(1): 1-26.

Goldin, Claudia D., and Lawrence F. Katz. 2008. The Race Between Education and Technology. Cambridge, Mass.: Belknap Press.

Goldin, Claudia D., and Robert A. Margo 1992. The Great Compression: The Wage Structure in the United States at Mid-Century. Quarterly Journal of Economics 107(1): 1-34.

Goldstone, Jack A. 2002. Efflorescence and Economic Growth in World History: Rethinking the "Rise of the West" and the Industrial Revolution. Journal of World History 13(2): 323-89.

Grossman, Gene M., and Elhanan Helpman. 1991. Innovation and Growth in the Global Economy, Cambridge, Mass.: MIT Press.

Hansen, Gary D., and Edward C. Prescott. 2002. Malthus to Solow. American Economic Review 92(4): 1205-17.

Hazan, Moshe, and Berdugo, Binyamin. 2002. Child Labour, Fertility, and Economic Growth. Economic Journal 112(482): 810-28.

Heckman, James J., Lance J. Lochner, and Petra E. Todd 2008. Earnings Functions and Rates of Return. Journal of Human Capital 2(1): 1-31.

Hobsbawm, E. J. 1952. The Machine Breakers. Past and Present 1(1): 57-70.

Horrell, Sara, and Jane Humphries. 1995. "The Exploitation of Little Children": Child Labor and the Family Economy in the Industrial Revolution. Explorations in Economic History 32(4): $485-516$.

Humphries, Jane. 2010. Childhood and Child Labour in the British Industrial Revolution. Cambridge: Cambridge University Press.

Jones, Charles I. 1998. Introduction to Economic Growth. New York: W.W. Norton \& Company.

Jones, Charles I. 2001. Was the Industrial Revolution Inevitable? Economic Growth over the Very Long Run. Advances in Macroeconomics 1(2): 1028-28.

Katz, Lawrence F., and David H. Autor. 1999. Changes in the Wage Structure and Earnings Inequality. In Handbook of Labor Economics, volume 3A, edited by O. Ashenfelter and D. Card. 
Amsterdam: North Holland, pp. 1463-1555.

Katz, Lawrence F., and Kevin M. Murphy. 1992. Changes in Relative Wages, 1963-87: Supply and Demand Factors. Quarterly Journal of Economics 107(1): 35-78.

Kremer, Michael. 1993. Population Growth and Technological Change: One Million B.C. to 1990. Quarterly Journal of Economics 108(3): 681-716.

Kuczynski, Robert R. 1969. The Measurement of Population Growth. Revised edition. New York: Gordon and Breach Science Publishers, Inc.

Lucas, Robert E. 2002. The Industrial Revolution: Past and Future. In Lectures on Economic Growth. Cambridge, Mass.: Harvard University Press, pp. 109-88.

Maddison, Angus. 1995. Monitoring the World Economy 1820-1992. Paris: OECD.

Maddison, Angus. 2001. The World Economy: A Millennial Perspective. Paris: OECD.

Mitch, David. 1982. The Spread of Literacy in Nineteenth-Century England. Ph.D. dissertation, University of Chicago. Unpublished.

Mitch, David. 1992. The Rise of Popular Literacy in Victorian England: The Influence of Private Choice and Public Policy. Philadelphia: University of Pennsylvania Press.

Mitch, David. 1999. The Role of Education and Skill in the First Industrial Revolution. In The British Industrial Revolution: An Economic Perspective edited by J. Mokyr. 2nd edition. Boulder, Colo.: Westview Press, pp. 241-79.

Mitchell, B.R. 1988. British Historical Statistics. Cambridge: Cambridge University Press.

Mokyr, Joel. 1999. The British Industrial Revolution: An Economic Perspective. 2nd edition. Boulder, Colo.: Westview Press.

Mokyr, Joel. 2002. The Gifts of Athena. Princeton, N.J.: Princeton University Press.

Mokyr, Joel. 2005a. Long-Term Economic Growth and the History of Technology. In Handbook of Economic Growth, volume 1, edited by P. Aghion and S. Durlauf. Amsterdam: North Holland, pp. $1113-80$.

Mokyr, Joel. 2005b., The Intellectual Origins of Modern Economic Growth. Journal of Economic History 65(2): 285-351.

Mokyr, Joel, and Hans-Joachim Voth. 2010. Understanding Growth in Europe, 1700-1870: Theory and Evidence. In The Cambridge Economic History of Modern Europe, volume 1. Cambridge: Cambridge University Press, pp. 7-42.

Murphy, Kevin M., W. Craig Riddell, and Paul M. Romer. 1998. Wages, Skills and Technology in the United States and Canada. In General Purpose Technologies and Economic Growth edited by E. Helpman. Cambridge, Mass.: MIT Press, pp. 283-309.

Nardinelli, Clark. 1990. Child Labor and the Industrial Revolution. Bloomington, Ind.: Indiana University Press.

North, Douglass, and Barry Weingast. 1989. Constitutions and Commitment: Evolution of Institutions Governing Public Choice in Seventeenth Century England. Journal of Economic History 49(4): $803-32$. 
Prados de la Escosura, Leandro. 2012. World Human Development: 1870-2007. Universidad Carlos III. Unpublished.

Romer, Paul. 1990. Endogenous Technological Change. Journal of Political Economy 98(5): S71-102.

Schmitt, John. 1995. The Changing Structure of Male Earnings in Britain, 1974-1988. In Differences and Changes in Wage Structures edited by R. Freeman and L. Katz. Chicago: University of Chicago Press and NBER, pp. 177-204.

Schofield, Roger S. 1968. The Measurement of Literacy in Pre-Industrial England. In Literacy in Traditional Societies edited by J. Goody. Cambridge: Cambridge University Press, pp. 311-25.

Schofield, Roger S. 1973. Dimensions of Illiteracy, 1750-1850. Explorations in Economic History 10(4): 437-54.

Schumpeter, Joseph A. 1934. The Theory of Economic Development. Cambridge, Mass.: Harvard University Press.

Sokoloff, Kenneth L. 1984. Was the Transition from the Artisan Shop to the Non-Mechanized Factory Associated with Gains in Efficiency? Evidence from U.S. Manufacturing Censuses of 1820 and 1850. Explorations in Economic History 21(4): 351-82.

Tan, Jee-Peng, and Michael Haines. 1984. Schooling and Demand for Children: Historical Perspectives. World Bank Staff Working Papers no. 695.

Teulings, Coen N. 1995. The Wage Distribution in a Model of the Assignment of Skills to Jobs. Journal of Political Economy 103(2): 280-315.

Trostel, Philip A. 2004. Returns to Scale in Producing Human Capital from Schooling. Oxford Economic Papers 58(3): 461-84.

Trostel, Philip A. 2005. Nonlinearity in the Return to Education. Journal of Applied Economics 8(1): 191-202.

van Zanden, Jan Luiten. 2009. The Skill Premium and the "Great Divergence." European Review of Economic History 13(1): 121-53.

Voth, Hans-Joachim. 2003. Living Standards During the Industrial Revolution: An Economist's Guide. American Economic Review 93(2): 221-26.

Weisdorf, Jacob. 2004. From Stagnation to Growth: Revisiting Three Historical Regimes. Journal of Population Economics 17(3): 455-72.

West, E. G. 1975. Education and the Industrial Revolution. London: Batsford.

Williamson, Jeffrey G. 1982. The Structure of Pay in Britain, 1710-1911. Research in Economic History 7: 1-54.

Williamson, Samuel H. 2004. An Index of the Wage of Unskilled Labor from 1774 to the Present. Economic History Services, December. http:/ / eh.net.

Wrigley, E. A., and Roger S. Schofield. 1981. The Population History of England 1541-1871. Cambridge: Cambridge University Press. 


\section{Appendix 1: Limit Pricing and the Gains from Innovation}

Here we solve for the price new innovators would charge for newly invented machines in the face of competition from producers of older machines. First, let us describe the producers of the unskilled-intensive good, $A_{l} L$; analogous results will hold for the skill-intensive good. The production function for these goods are

$$
\left(\frac{1}{1-\beta}\right) Q_{l} L^{\beta} \int_{0}^{1} M_{l}(j)^{1-\beta} d j
$$

Producers wish to maximize profits or, equivalently, to minimize unit costs. The unit costs for producers who buy new machines, denoted as $u c$, can be written as

$$
u c=\beta^{-\beta}(1-\beta)^{\beta}\left(\frac{1}{\varepsilon Q_{l}}\right) w_{l}^{\beta} \int_{0}^{1} p(j)^{1-\beta} d j
$$

where $p(j)$ is the price of machine $j$ and $w_{l}$ is the wage of $L$.

The question for us is, what maximum price could an innovator charge and drive out the competition at the same time? The "competition" in this case are those who hold the blueprints of the next highest-quality machines of quality $Q_{l}$. The lowest price they can charge is their marginal cost, $Q_{l}$; if all old machine-producers charge this, unit costs can be written as

$$
u c_{\text {old }}=\beta^{-\beta}(1-\beta)^{\beta}\left(\frac{1}{Q_{l}}\right) w_{l}^{\beta} Q_{l}^{1-\beta} .
$$

Traditional endogenous growth theories that use quality ladders typically have producers of new machines charge a monopolistic mark-up over marginal cost. In our case producers of new machines would charge a price $p_{\text {monop }}=\frac{\varepsilon Q_{l}}{(1-\beta)}$ for a machine of quality $\varepsilon Q_{l}$. However, in order for this to be a profitable strategy, unit costs for producers of $A_{l} L$ must be at least as low when they buy new machines compared with when they buy the older, cheaper machines. In other words, $u c_{\text {old }} \geq u c_{\text {monop }}$, which requires that

$$
\beta^{-\beta}(1-\beta)^{\beta}\left(\frac{1}{Q_{l}}\right) w_{l}^{\beta} Q_{l}^{1-\beta} \geq \beta^{-\beta}(1-\beta)^{\beta}\left(\frac{1}{\varepsilon Q_{l}}\right) w_{l}^{\beta}\left(\frac{\varepsilon Q_{l}}{(1-\beta)}\right)^{1-\beta} .
$$

This simplifies to the condition $\varepsilon \geq(1-\beta)^{\frac{\beta-1}{\beta}}$. Thus, in order for monopoly pricing to prevail, quality improvements must be large enough for goods-producers to be willing to pay the higher price. If this condition does not hold, the monopoly-priced machine will be too expensive, and producers will opt for the older machines.

However, producers of newer machines can charge a price lower than this and still turn a profit. How low would they have to go to secure the market? They certainly could go no lower than $\varepsilon Q_{l}$, which is their own marginal cost of machine production. Fortunately they would not 
have to go that low; they could charge a price $p_{\text {limit }}$ low enough such that $u c_{\text {old }} \geq u c_{\text {limit }}$ (see Barro and Sala-i-Martin 2003 and Grossman and Helpman 1991 for similar limit-pricing treatments). That is, producers of new machines could undercut their competition so that goods-producers would prefer the higher-quality machines to the older lower-quality machines. And to maximize prices, new machines producers would charge a price such that this held with equality, so that

$$
\beta^{-\beta}(1-\beta)^{\beta}\left(\frac{1}{Q_{l}}\right) w_{l}^{\beta} Q_{l}^{1-\beta}=\beta^{-\beta}(1-\beta)^{\beta}\left(\frac{1}{\varepsilon Q_{l}}\right) w_{l}^{\beta} p_{\text {limit }}^{1-\beta} .
$$

Solving for this limit price gives us

$$
p_{\text {limit }}=\varepsilon^{\frac{1}{1-\beta}} Q_{l}>\varepsilon Q_{l}
$$

Thus, producers will always opt for newer machines, no matter the size of quality steps. So our approach would be valid for any values of $\varepsilon>1$ and $0<\beta<1$. Given our paramerization described in section 2.3, we assume this limit pricing strategy is used.

\section{Appendix 2: Additional Robustness Analysis}

Here we observe simulation results with other alternative parameter values. We first try alternative lower values of $k$, which governs the human capital returns from education. Specifically, $k$ is lowered from its baseline value of 1.5 , first to a small, diminishing-returns levelvalue of 0.5 in Figure 12, and then raised to the constant-returns level of 1 in Figure 13. (In order to keep the skill premium at a reasonable number slightly less than 2, we also increase $\tau$ to 0.63 and 0.53 , respectively, in these cases, and adjust we $\delta$ to keep the transition in the same 10 year window). Again, we see that general patterns for fertility, education and wages remain the same. Thus our results are not sensitive to the specific rate of return from education.

Figure 14 displays simulation results for the case of even greater increasing returns to education that in the baseline case. Specifically, the parameter $k$ is increased from its baseline value of 1.5 to a level of 2 . (To set a reasonable starting value for the skill premium in this case, $\tau$ is lowered to 0.37 , and we again adjust $\delta$ to keep the transition in the same 1o year window). In this case the skill premium actually rises initially, before falling later. This shows that the model can still qualitatively match the data, even if there remains an empirical dispute over the direction of the change in the skill premium during the early Industrial Revolution.

Finally, Figure 15 displays simulation results for the case of a larger "fishing-out" effect. In this case innovation dramatically raises the costs for future innovations. Notice that this makes growth in unskilled technologies sporadic. Despite this, the evolution for fertility, education and wages echo those of prior simulations, albeit with some added choppiness. 


\section{Figure 12: Robustness Check 5}

The figure shows the model simulation when $k=0.5$.
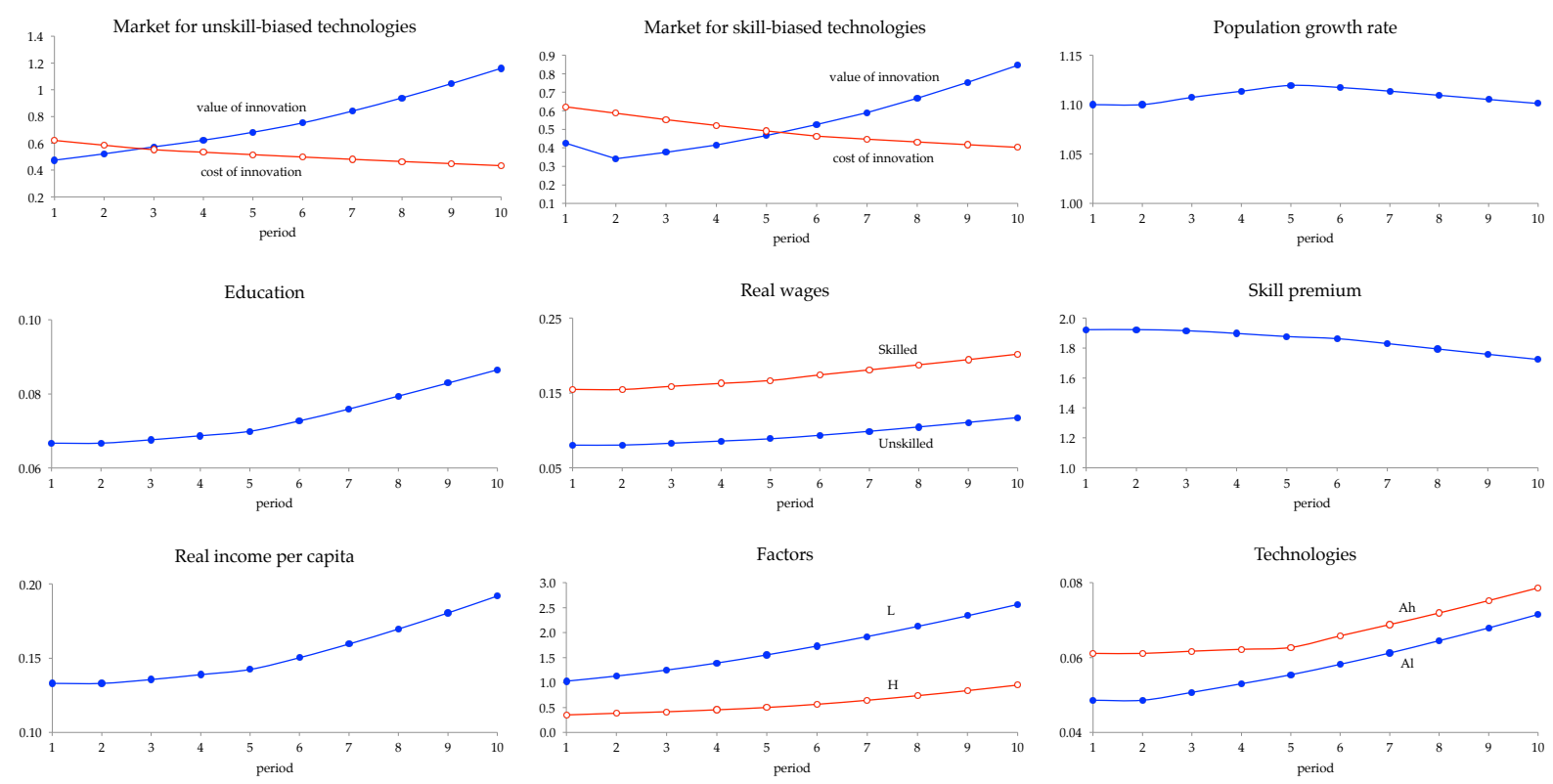

\section{Figure 13: Robustness Check 4}

The figure shows the model simulation when $k=1$.
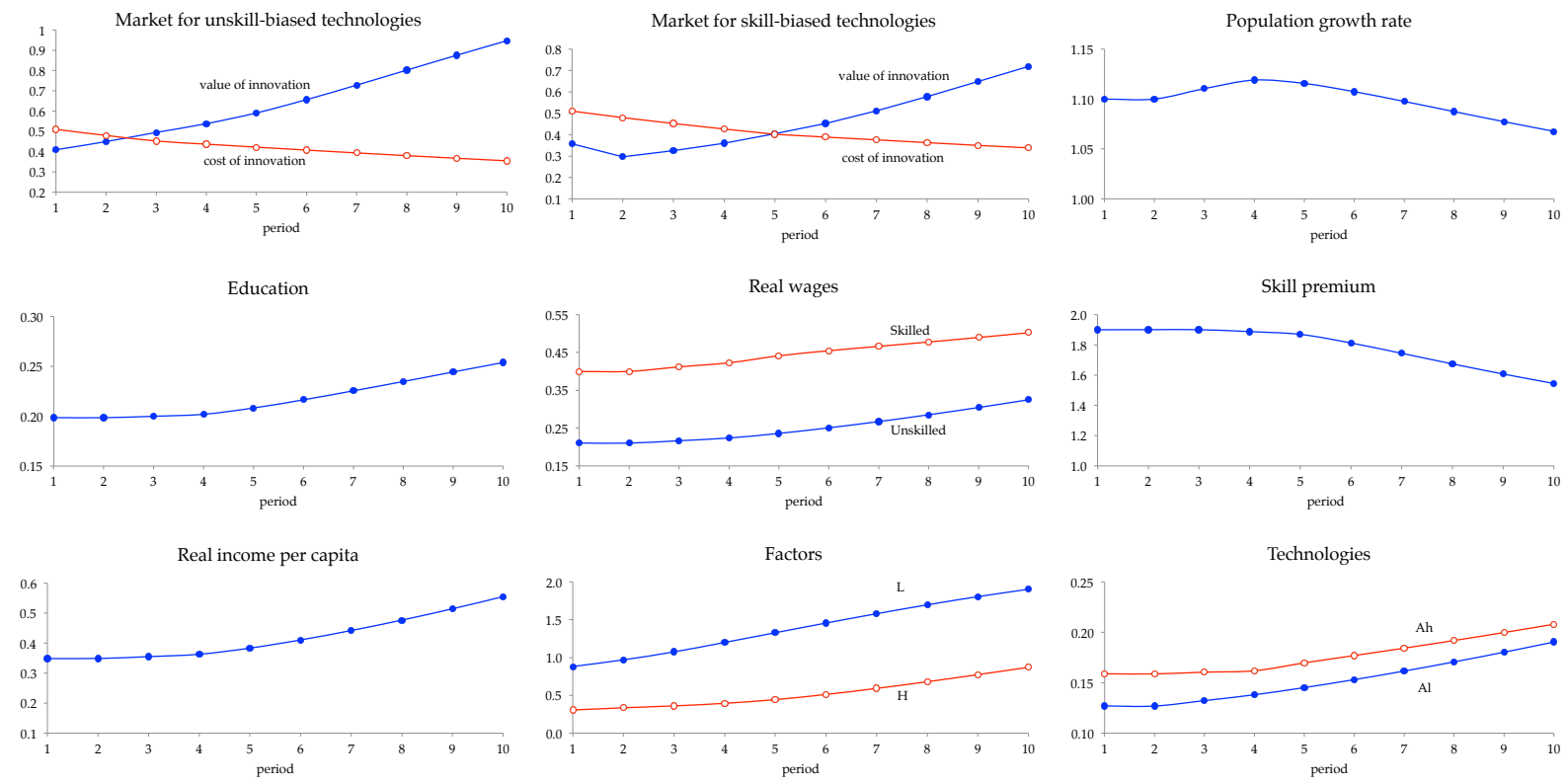


\section{Figure 14: Robustness Check 6}

The figure shows the model simulation when $k=2$.
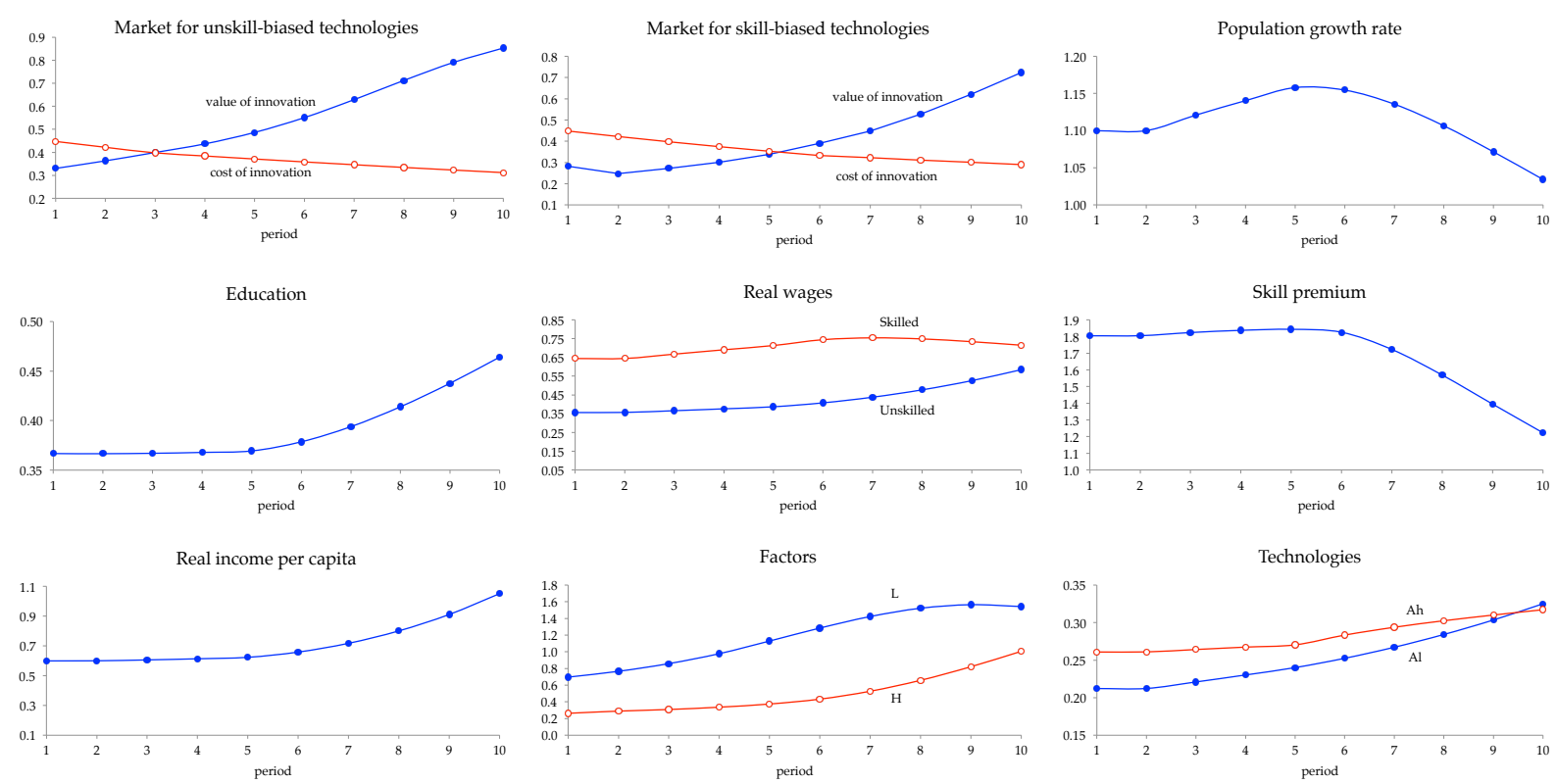

\section{Figure 15: Robustness Check 6}

The figure shows the model simulation when $\alpha=5$.
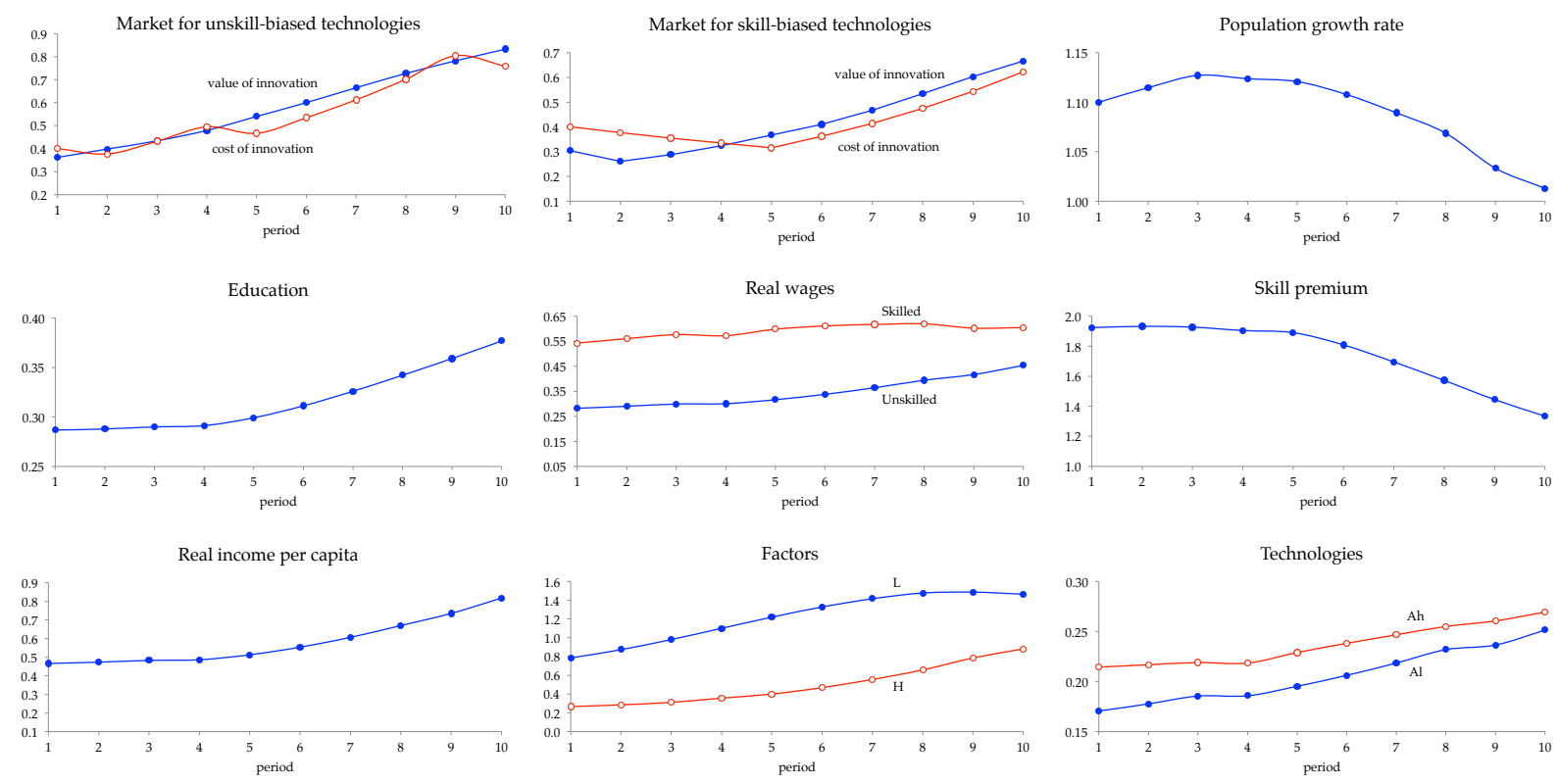